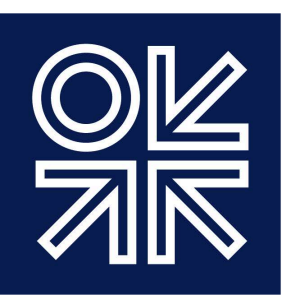

THE OXFORD

INSTITUTE

FOR ENERGY

STUDIES

\title{
Quantity Performance Payment by Results
}

Operationalizing enhanced direct access for mitigation at the Green Climate Fund

\section{Benito Müller, Samuel Fankhauser, and Maya Forstater}

\author{
EV 59 \\ July 2013
}


The contents of this paper are the authors' sole responsibility. They do not necessarily represent the views of the Oxford Institute for Energy Studies or any of its members.

This document is an output from a project funded by the UK Department for International Development (DFID) and the Netherlands Directorate-General for International Cooperation (DGIS) for the benefit of developing countries. However, the views expressed and information contained in it are not necessarily those of or endorsed by DFID, DGIS, or the entities managing the delivery of the

Climate and Development Knowledge Network, which can accept no responsibility or liability for such views, completeness or accuracy of the information, or for any reliance placed on them.

\section{Copyright $@ 2013$}

\section{Oxford Institute for Energy Studies}

(Registered Charity, No. 286084)

This publication may be reproduced in part for educational or non-profit purposes without special permission from the copyright holder, provided acknowledgment of the source is made. No use of this publication may be made for resale or for any other commercial purpose whatsoever without prior permission in writing from the Oxford Institute for Energy Studies.

ISBN: 978-1-907555-78-7

\section{Authors}

Dr Benito Müller is Director, Energy and Climate Change, at the OIES, and Managing Director of Oxford Climate Policy. A list of his publications can be found at www.OxfordClimatePolicy.org.

Email: benito.mueller@philosophy.ox.ac.uk.

Prof. Samuel Fankhauser is Co-Director of the Grantham Research Institute, and a Fellow of the Centre for Climate Change Economics and Policy, London School of Economics.

Email: s.fankhauser@1se.ac.uk.

Ms Maya Forstater is an independent researcher.

Email: hiyamaya@gmail.com.www.hiyamaya.wordpress.com

\section{Acknowledgments}

We would like to thank the Climate and Development Knowledge Network

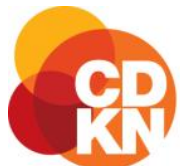

funding this publication (www.cdkn.org).

We would also like to thank, without implication, Silvie Kreibiehl, Andrew Reicher, Oliver Knight, Hans Olav Ibrekk, Michelle De Nevers, Marte Nordseth, Neil Bird, Phil Lewis, and John Ward for their valuable inputs and comments. Fankhauser also acknowledges support from the Grantham Foundation for the Protection of the Environment and the UK Economic and Social Sciences Research Council (ESRC) through the Centre for Climate Change Economics and Policy. 


\section{Contents:}

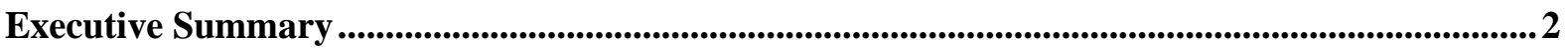

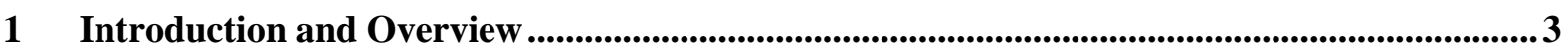

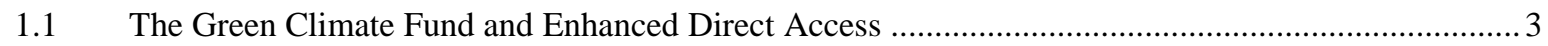

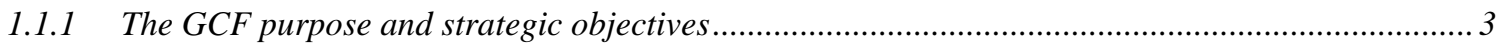

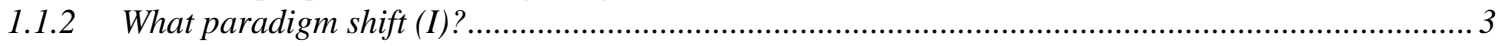

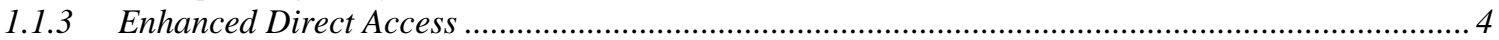

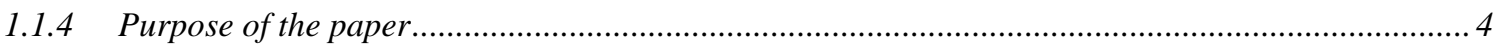

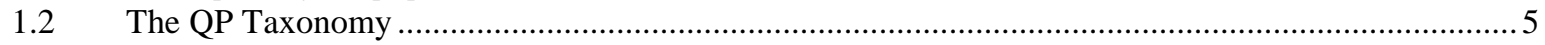

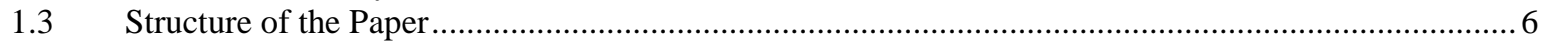

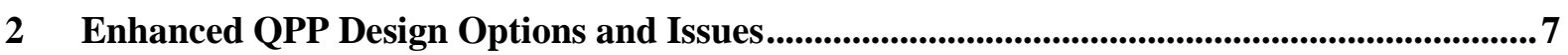

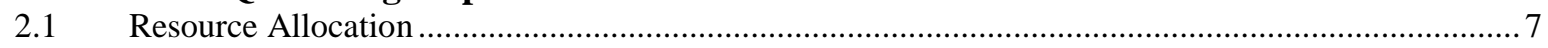

2.2 The core elements of QPP instruments and transactions .............................................................. 8

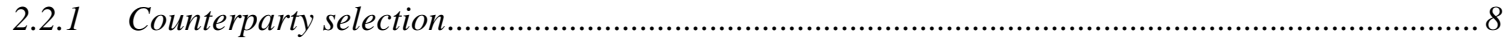

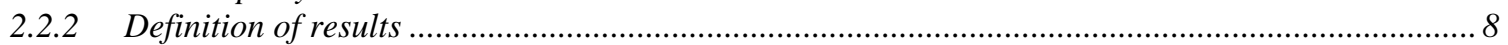

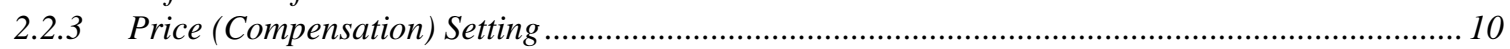

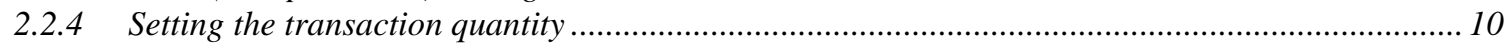

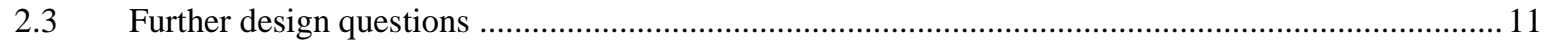

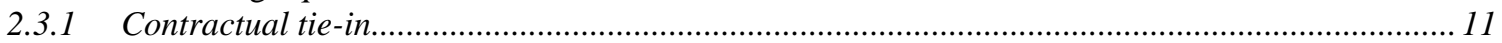

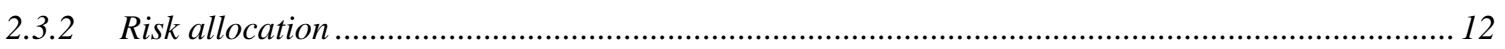

2.3.3 Interaction with other mechanisms ................................................................................. 12

3 Early Experiments and Conceptualizations ............................................................................................ 14

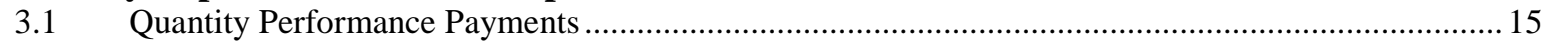

3.1.1 The Norwegian International Forest Climate Initiative (NICFI) .................................................... 15

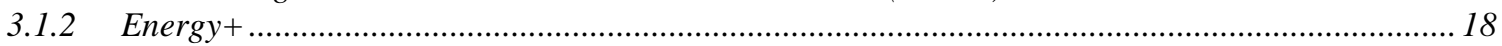

3.1.3 Center for Global Development: Rewarding Accelerated Transition Pathways ............................ 20

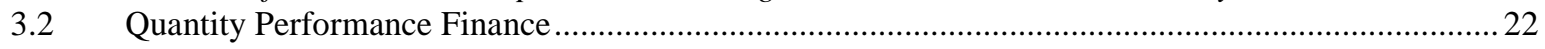

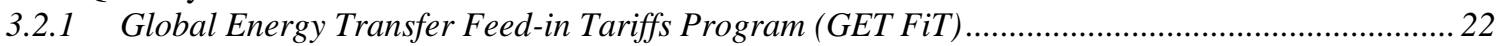

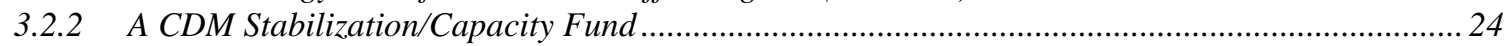

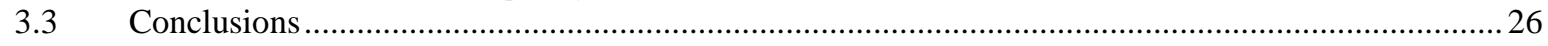

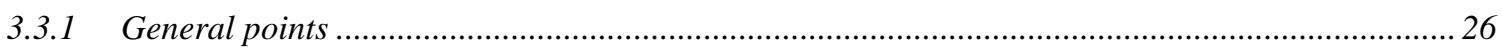

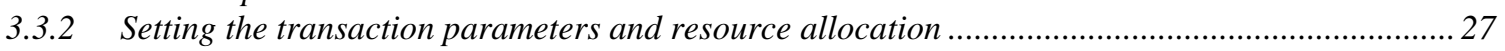

4 Evaluation of the enhanced QPP Approach ..........................................................................................28

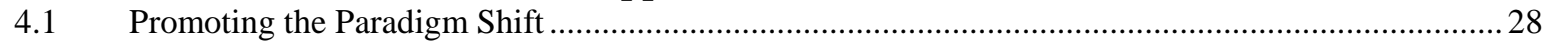

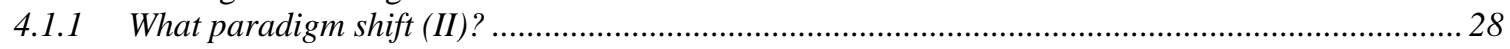

4.1.2 Single result quantities or sets of result quantities ................................................................... 28

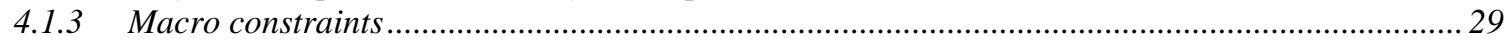

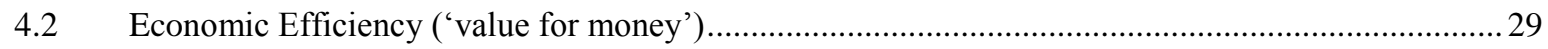

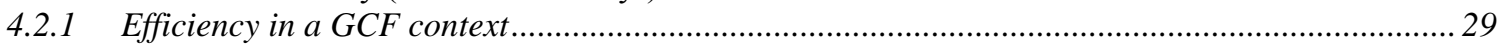

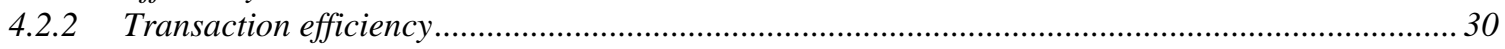

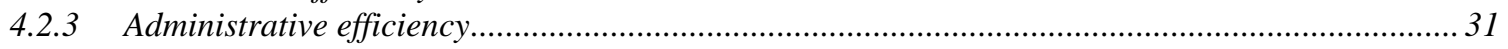

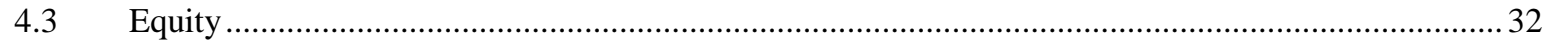

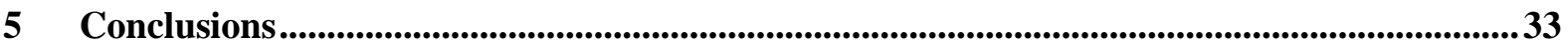

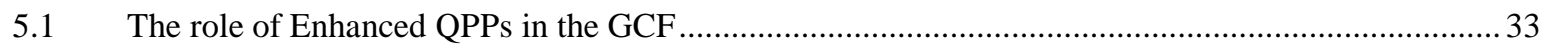

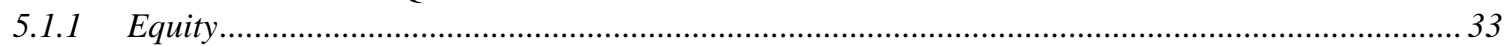

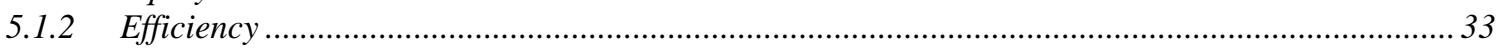

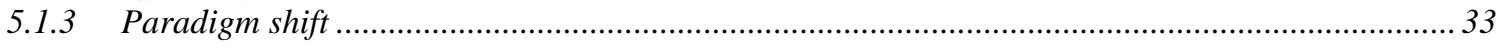

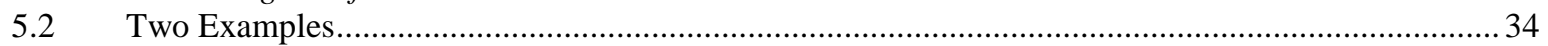

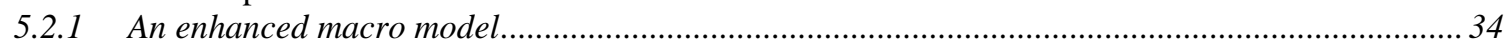

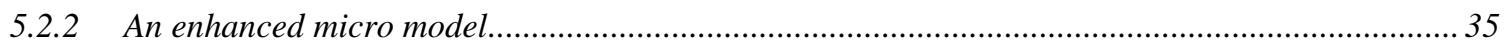

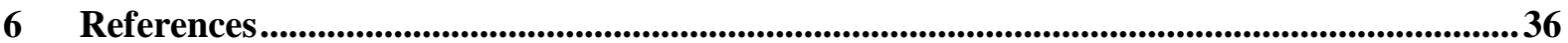




\section{Executive Summary}

On 28 June 2013 the Green Climate Fund (GCF) Board decided to consider at its first meeting in 2014 additional modalities that further enhance direct access, including through funding entities with a view to enhancing country ownership of projects and programs. This paper addresses the question of whether a certain type of funding mechanisms, known as Quantity Performance Payments (QPPs), could be used to fund mitigation activities in developing countries in the context of what has become known as 'enhanced direct access' through (national or regional) funding entities.

QPP is about rewarding mitigation performance measured in terms of some (physical) quantity. As part of a wider set of support windows, it could be an effective way for the GCF to meet its objectives of achieving climate change mitigation at scale, while providing enhanced direct access. It warrants further exploration by the GCF.

The paper starts with an introduction to the Green Climate Fund and enhanced direct access and continues with an overview of concepts and classifications regarding Quantity Performance (QP) instruments. It then turns to describe in detail the main design options and issues regarding QPPs, in particular the issue of resource allocation and four core elements of QPP transactions: namely counterparty selection, definition of results, price setting, and the setting of transaction quantities.

There are different ways in which these features can be determined, transaction by transaction. For example, counterparties and price could be determined competitively through auctions, or they could be set through negotiation on a first-come-first served basis, or by using a standard formula. Similarly QPP transactions may be micro in structure (in other words, they could be structured as the aggregation of performance measured in smaller, decentralized activities, perhaps led by the private or third sector) or macro (rewarding performance measured at a national, sub-national, or sectoral level). The way in which these elements are determined fundamentally defines the nature of a QPP instrument. The GCF will have to develop a view on the design features that are most suitable for its purposes.

This paper considers some early experiments and conceptualizations of using QP instruments at a macro- and a micro-level. Examples of the former, discussed in this paper, are the Norwegian International Forest Climate Initiative (NICFI), the Energy+ programme, and a scheme to reward accelerated transition pathways proposed by the Center for Global Development. The Global Energy Transfer Feed-in Tariffs (GET FiT) program and a proposal for a Clean Development Mechanism (CDM) Stabilization/Capacity Fund are examined as examples of QP models involving micro-level results. This Section concludes that all these examples provide useful starting points, but none of them yet offers a fully operational approach to enhanced direct access.

The paper then carries out an evaluation of QP instruments in the context of enhanced direct access, with respect to three key objectives of the GCF, namely, to promote a paradigm shift towards low-emission and climate-resilient development pathways, to achieve economic efficiency in directly securing emission reductions at cost, and to support equity in the distribution of resources. Based on this evaluation, the paper concludes that enhanced QPPs can be used in conformity with these objectives, provided they are used as a complement to other funding instruments. Finally, the paper puts forward two enhanced models - building on the example of the NICFI and the idea of a CDM Capacity Fund - as illustrations of how enhanced QPPs could be structured in the context of macroor micro-level results, and with competitive or standardized transactions. 


\section{Introduction and Overview}

It has been estimated that to have a good chance of limiting climate change to a rise in global average temperature of below $2^{\circ} \mathrm{C}$, no more than about $1,000 \mathrm{GtCO}_{2}$ can be emitted globally between now and 2050 (Carbon Tracker, 2013). Annual greenhouse gas emissions would have to be cut from around 50 $\mathrm{GtCO}_{2} \mathrm{e}$ today to around $20 \mathrm{GtCO}_{2} \mathrm{e}$ or less by 2050 (Bowen and Ranger, 2009). Perhaps as much as 70 per cent of the required emission cuts would, most cost effectively, take place in developing countries, at an incremental cost of between US $\$ 250-560$ billion annually by 2030 (World Bank, 2010).

\subsection{The Green Climate Fund and Enhanced Direct Access}

\subsubsection{The GCF purpose and strategic objectives}

The purpose of the newly established Green Climate Fund (GCF), according to its Governing Instrument, is:

... to make a significant and ambitious contribution to the global efforts towards attaining the goals set by the international community to combat climate change. ${ }^{l}$

The Fund will:

... play a key role in channelling new, additional, adequate and predictable financial resources to developing countries and will catalyse climate finance, both public and private, and at the international and national levels. ${ }^{2}$

The first section of the GCF Governing Instrument lists objectives and guiding principles. At least three strategic objectives can be identified: the GCF should
(i) be efficient and effective,
(ii) be equitable, and
(iii) promote a certain paradigm shift.

None of these terms is self-explanatory and indeed one of them is only alluded to by proxy. ${ }^{4}$

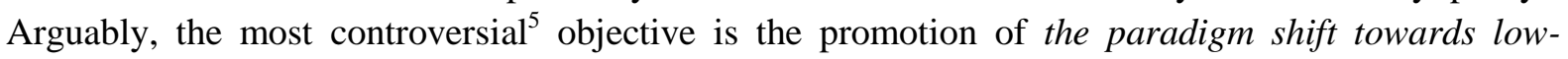
emission and climate-resilient development pathways.

\subsubsection{What paradigm shift (I)?}

It is beyond the scope of this paper to analyse the meaning of 'paradigm shift' as used in the Governing Instrument in any detail. Nonetheless, as we will have to consider whether QP instruments

\footnotetext{
${ }^{1}$ Instrument of the Green Climate Fund, Para. 1, emphasis added.

${ }^{2}$ Op. cit. Paragraph 3.

${ }^{3}$ The Fund will [be] guided by efficiency and effectiveness. ... The Fund will strive to maximize the impact of its funding ....

${ }^{4}$ The notion of 'equity' is not explicitly used in the Governing Instrument, but it does specify that The Fund will be guided by the principles and provisions of the Convention, which, in turn includes the Principle of Equity. While there are many forms of equity that could be evoked in this context, the one which we will consider, and which is of paramount importance, is distributional equity in the context of resource allocation.

${ }^{5}$ Some of the questions in the Co-Chairs' list fall outside the jurisdiction of this Board I am afraid. A matter of significance and strategic importance is that the GCF should not decide for the COP. For example, I noticed among the questions the Chairs are asking for clarification, questions on terms such as: 'paradigm shift towards low-emissions', and also 'low emission development strategies'. As you know, the AWG-LCA or the COP did not elaborate these and other similar terms. Unilateral interpretation of such terms by the GCF may have uncertain consequences. Therefore, the GCF Board should ask the COP for guidance on such matters, per paragraph 6(a) of the Governing Instrument.[Salman Aldossary, Alternate GCF Board member, Saudi Arabia, in Views by Members and Alternate members of the Board of the Green Climate Fund On Questions related to the Fund's Business model framework, Interim Secretariat of the GCF.]
} 
can be used in a manner that is compatible with the GCF objective, we do need to say something about it. In order to promote whatever the shift may be, the GCF will have to promote appropriate changes in the policies and incentives which currently drive investment, production, and consumer behaviour into carbon-intensive and non-resilient activities. However, these changes will not only have to be appropriate, in the sense of contributing to the envisaged paradigm shift, they - and indeed the resulting development pathway - will have to be acceptable to the countries in question.

\subsubsection{Enhanced Direct Access}

An important feature of the GCF, both with respect to the up-scaling of financial flows and to the acceptability of the envisaged paradigm shift, is hence the enhanced direct access by national governments through national funding entities. The GCF Instrument stipulates that:

... the Fund will provide simplified and improved access to funding, including direct access (Paragraph 31).

To this end:

... recipient countries will nominate competent subnational, national and regional implementing entities for accreditation to receive funding. The Board will consider additional modalities that further enhance direct access, including through funding entities with a view to enhancing country ownership of projects and programmes.(Paragraph 47, emphasis added)

It is envisaged that Funding Entities (FEs) will be legal entities that draw GCF funding in order to approve and fund eligible activities. National Funding Entities (NFEs), in turn, are FEs which - like the Bangladeshi Climate Chance Resilience Fund - are 'government owned', in other words, they are managed by the governments that have jurisdiction over the emissions the funding is meant to help address. This devolution of project and programme decisions to (in-country ${ }^{6}$ ) NFEs, it has been argued, enhances not only the legitimacy of the funding, but also its effectiveness and efficiency (Müller, 2011). By allowing for funding decisions to be managed at the local level, national ownership and commitment is supported through the ability to integrate climate finance into national planning processes (Gomez-Echeverri, 2010). Furthermore, given the scale of the funding needed, even if only a fraction of these costs is met by the GCF, this may help to overcome the challenges and costs of disbursement using traditional centralized funding modalities (Ciplet et al., 2010).

\subsubsection{Purpose of the paper}

The purpose of this paper is to analyse whether and how Quantity Performance (QP) methods rewarding mitigation performance measured in terms of some (physical) quantity - could be an effective way for the GCF to meet its objectives of achieving climate change mitigation at scale, specifically in the context of providing enhanced direct access.

The GCF will clearly have to provide the option of traditional (ex ante) project/programme-based funding, not only in relation to capacity building and adaptation but also to mitigation. However, this paper argues that a QP-based funding mechanism for mitigation could have significant attractions to the GCF. One of the main attractions of a QP approach to funding these NFEs is that it lends itself very naturally to the underlying devolved decision making architecture. Tying payment to quantified results would enable funders to take a more hands-off approach to determining how funds are used, releasing resources after results are verified, thus supporting greater country ownership and incentivizing performance delivery.

\footnotetext{
${ }^{6}$ It is conceivable that NFEs, in this sense, are 'sub-national' institutions run by sub-national governments, or indeed 'regional' in the sense of comprising multiple governments (say if it does not make sense to have an NFE, say for reason of administrative efficiency - as might be the case for certain Pacific SIDS). The key is that the governments in question actually take the relevant funding decisions.
} 


\subsection{The QP Taxonomy}

Quantity Performance funding instruments are part of the relatively new and evolving domain of results-based funding approaches which have been pioneered, particularly in the field of development cooperation, ${ }^{7}$ as a means to target funding towards cost-effective results. Although a firm empirical basis is only just emerging there is a sense that, with certain preconditions, resultsbased funding can help to align further the objectives of donors and recipients, and therefore reduce delivery risk. The preconditions include: a reasonable control over outcomes by the partner, a performance-oriented culture in the partner country, and acceptable monitoring costs (for examples, see: Birdsall and Savedoff, 2011, 2013; Parks and Rice 2013; Klingebiel, 2012; Vivid Economics, 2013a).

While, as illustrated in Figure 1, these results-based approaches are not necessarily tied to quantitative outcomes $^{8,9}$ Quantity Performance (QP) instruments are, by definition, intended to measure performance in quantitative terms. Indeed, in this paper we use ' $Q P$-instrument' as an umbrella term for greenhouse gas mitigation activities for which payments are tied to results defined in a measurable physical quantity, such as tonnes of $\mathrm{CO}_{2}$, $\mathrm{kWh}$ of renewable energy, or hectares of forests. ${ }^{10}$ The second defining characteristic of QP instruments is that of performance-based ('on delivery', 'ex post') payment, rather than ex ante funding linked to the provision of particular inputs.

Although there is as yet no agreed terminology for results-based funding, one distinction that is becoming increasingly common is that between 'payments by results' and 'results-based finance'. For the purposes of this paper, we shall use the term payment by results ('payment', for short) as referring to the provision of funding by international public funders to a domestic government/funding agency for (predetermined) results. By results-based finance ('finance') we mean the provision by public funders of incentives to delivery agents (executing entities) - private companies or state agencies - for the delivery of (predetermined) results or outputs.

The use of QP instruments in financing private sector activities is the topic of an earlier OIES Energy and Environment Brief - 'Mobilizing the Private Sector - Quantity-Performance Instruments for Public Climate Funds' (Ghosh et al., 2012). Many of the issues discussed in this 'sister' Brief are also relevant for QP payments, and will be cross-referenced accordingly in order to focus on those issues that are specific to QP Payment by result (QPP). While it is, in principle, possible to use QPP instruments to provide funding for multilateral funding entities, the focus of this paper is on enhanced direct access QPP (enhanced QPP), used in providing resources to National Funding Entities, as characterized in the preceding Section.

\footnotetext{
${ }^{7}$ Terms such as 'results/performance/output based aid', 'payment by results', 'cash-on-delivery', have all been used to describe similar concepts. The common features are that there a deal between a funder and an agent, to release (pre-agreed) payments for achieving (predefined) results, subject to monitoring and verification (Yogita et al., 2010).

${ }^{8}$ Results or performance can also be 'measured' in a more qualitative manner, for example by reference to expert judgment-based rankings or indices - such as the World Bank's IDA Resource Allocation Index (IRAI), as based on the results of the annual Country Policy and Institutional Assessment (CPIA).

${ }^{9}$ The World Bank Program-for-Results, for example, pays out on 'Disbursement Linked Indicators' which are project-specific milestones.

${ }^{10}$ Not GEF-style barrier removals, or technical assistance (which also have an important place, but not for the present purposes).
} 


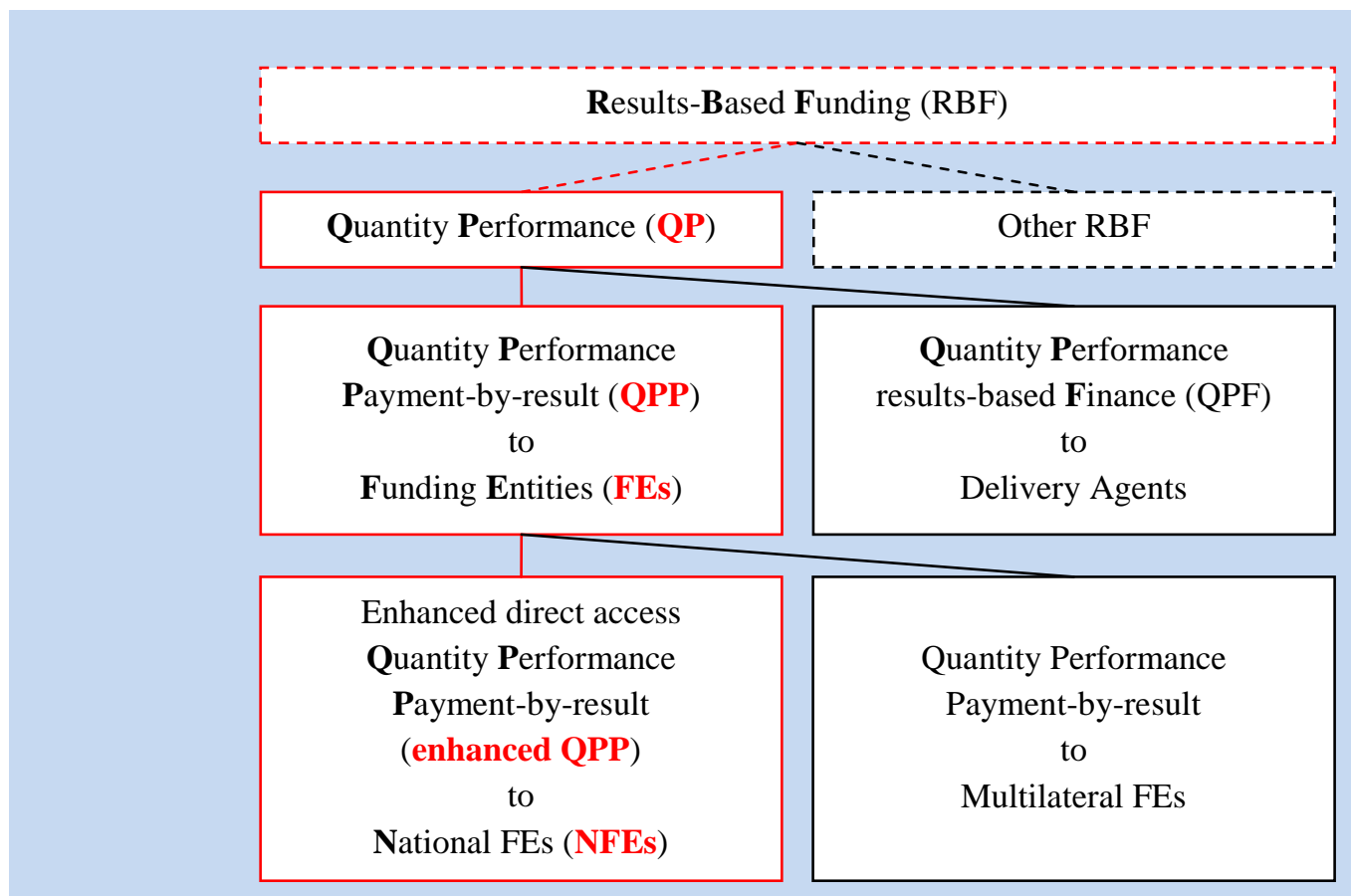

Figure1. The QP Taxonomy

\subsection{Structure of the Paper}

Designing an enhanced QPP instrument raises both practical and conceptual questions. Some of these are generic, while others are specific to enhanced QPP with NFEs/countries as recipients (such as the question of resource allocations to countries/NFEs, as introduced in Section 2.1).

The core elements of any $\boldsymbol{Q P}$-transaction ${ }^{11}$ are: a counterparty, a result (for example, emission reductions, measured in tonnes of $\mathrm{CO}_{2}$ ), a per unit transaction price, and an associated transaction quantity (Section 2.2). However, there are other issues that need to be taken into account in designing such instruments such as: timing (whether a transaction is entered into ex ante or ex post), the allocation of risk, and the interaction of QP-instruments with other efforts to mitigate greenhouse gases (Section 2.3).

There are already several examples of QPP-mechanisms which have been established in relation to climate change mitigation and related objectives, including experiments under Norway's International Forest Climate Initiative, Energy+, and the GET FiT Program. The Center for Global Development has also set out a proposed approach for cash-on-delivery funding for accelerated pathways of forest and energy transition. These will be introduced in Part 3.

Based on an understanding of the practical experience so far and the conceptual issues at hand, it becomes possible to evaluate the merits of enhanced QPP methods with respect to strategic GCF objectives (1.1.1). This will be done in Part 4 with regard to paradigm shift promotion (4.1) efficiency (4.2), and equity (4.3).

The Paper's Conclusions summarize the main results and puts forward two examples of how enhanced QPP instruments could be applied in the context of different socio-economic practices.

\footnotetext{
${ }^{11}$ Note that we use the term 'instrument' to refer to a type of transaction, and 'transaction' for activities (not necessarily of a sales/purchase nature) carried out under the instrument in question.
} 


\section{Enhanced QPP Design Options and Issues}

Enhanced QPP is broadly characterized by four key features: it is quantity-based, performance-based, direct access-oriented, and focused on securing emission reductions at scale. Part 2 looks at the options for designing such instruments and at some of the issues arising from different design options. Many of these issues and options pertain to QP-instruments in general, but enhanced QPP answers them in its own particular way. Enhanced QPP also raises some design issues that are particular to a mechanism of this kind.

This Part of the Paper begins by looking at a particular meta-issue concerning QPP instruments, namely the allocation of resources to recipient countries. It moves on to describe the core elements of enhanced QPP instruments (the elements that fundamentally define a transaction which must be specified to talk about transactions at all). Finally, it turns to some broader design issues that will influence the role and attractiveness of enhanced QPP for comprehensive emission reduction.

\subsection{Resource Allocation}

With resources being scarce, their allocation will be a key challenge for the GCF. There are likely to be allocations with respect to 'funding windows' (adaptation, mitigation), 'funding facilities', and 'modalities' (for example: private sector facility and direct access), as well as other categories such as countries, sectors, and programme types. ${ }^{12}$ Given our focus on enhanced QPP, the main resource allocation issue for this paper - following the decision on how much should be set aside for (enhanced) QPP - is the allocation of resources within this envelope between countries, or between (sub-) national funding entities, qua recipients of QPPs.

It is important to emphasize that these allocations should not be confused with disbursements of funds in the course of individual transactions: 'Resource allocation' is here taken to refer to the process of setting aside/earmarking certain (minimum/maximum) amounts for certain types of themes and recipients, such as those mentioned above. With respect to funding instruments, this can be done exogenously or endogenously.

Exogenous Resource Allocations. An increasingly popular way of making exogenous allocations in multilateral funds is by way of a 'top-down' formula: a quantitative, centrally calculated yardstick to allocate scare resources - as pioneered by the International Development Association (IDA), the concessional lending arm of the World Bank. Allocations of IDA funds are based on an intricate formula that combines elements of need, competence, and past performance. The use of a similar approach for adaptation resources has been proposed by the World Bank (World Bank, 2010; also Barr et al., 2010). The Adaptation Fund Board has established a system which combines criteria to prioritize eligible projects and a funding cap per eligible country (Adaptation Fund, 2009). The GEF sets an 'indicative allocation' per country based on a combination of the scale of potential global environmental benefits, the quality of institutions, and the need for capacity building implied by social and economic indicators (GEF, 2011).

Endogenous Resource Allocations. A possible alternative to the use of top-down formulae is an implicit or 'endogenous' approach, where resource allocation is simply the outcome of all the transactions carried out under the chosen instrument over the period in question.

\footnotetext{
${ }^{12}$ These recipient-specific allocations may have to be done concurrently. Thus it could well be that one might wish to complement an allocation between mitigation and adaptation - or between sectors - with country allocations.
} 
Ultimately, the issue of resource allocation can only be discussed in the context of specific transaction instruments, and of whether they require corrective measures. We shall now proceed to describe the elements of such enhanced QPP instruments, and will turn to the allocation issues once these elements have been introduced, and exemplified with reference to existing models.

\subsection{The core elements of QPP instruments and transactions}

The design of a QPP instrument involves, in a first instance, decisions on certain core design elements. In this context it is useful to distinguish four core elements of a QPP instrument, namely:

- the counterparty (who to transact with),

- the result (nature and quality of the agreed outcome),

- the compensation (at what price),

- the quantity (how much to transact).

The four elements are interrelated. The level of compensation, for example, may be influenced by how narrowly the results and the transaction quantity are defined. A tightly structured transaction with strong counterparty contributions is likely to demand a higher price. The four elements may therefore be determined at the same time, and perhaps through the same tools: auctions, for example, may be used to set the price and quantity of a transaction as well as to select a counterparty. Equally, the GCF may employ different design combinations simultaneously, say, for different types of emission reductions.

\subsubsection{Counterparty selection}

All QPP transactions will be between the GCF and a counterparty - such as a government funding agency and/or a NFE. The selection of counterparties is related to the question of resource allocation, and will be influenced by the rules on resource allocation. For example, the choice of counterparties may be constrained by the country limits under a top-down allocation formula. Within the rules of the resource allocation framework there are at least three generic counterparty selection rules:

First come first served: Making decisions - on this basis is a common allocation method if resources are not overly constrained, but it allows little strategic choice. For this reason, even within organizations that follow this rule (such as the GEF, certainly in its early years) decisions are guided by support strategies that determine priorities. Most of the practical examples reviewed in Part 3 below are pilots of this kind.

Beauty contest: To introduce a soft element of competition, transactions may be awarded according to a broad set of more or less tangible criteria, such as the quality of the development plan, its social impact, or the strength of environmental side benefits. Beauty contests are rarely used in a development or environmental context but have been used when awarding licenses and franchises. For example, many countries have awarded mobile phone licenses through beauty contests rather than formal auctions.

Auctions: A stronger and more formal element of competition can be introduced through periodic auctions. Various auctioning mechanisms are conceivable (see Müller et al., 2012), with potential counterparties competing either on price, reference level, or a combination of the two (subject to certain technical standards).

\subsubsection{Definition of results}

A key aspect of a QPP transaction is a clear definition of the 'results' against which payments will be made. Results are defined, inter alia, along the following dimensions: 
Scope: Transactions are characterized in terms of their size and scope, which includes their spatial and sectoral reach. Linked to this question is the choice between macro- and micro-level transactions. Macro transactions are comprehensive national, sub-national, or sectoral programmes which are pursued through a centrally coordinated framework (similar to the Amazon Fund, see below). They are likely to involve a public entity (such as a national or regional government) and monitoring would be at an aggregate level, for example through macroeconomic quantities like carbon per unit of GDP. Micro-level transactions may be similar in ambition but results are achieved through the aggregation of smaller, decentralized activities, which demonstrate direct, additional emission reductions (similar to the idea of a CDM Fund, see 3.2.2). Micro transactions are more likely to include private or thirdsector agents, and monitoring (including the determination of reference levels) may be disaggregated into discrete project activities.

Duration: Related to the question of scope is the timeframe over which results are to be delivered. Particularly for macro transactions, the preference is likely to be for longer timeframes - given the time it can take for policy programmes to ramp up. Setting in motion a paradigm shift takes time. However, longer programmes also reduce flexibility and the ability to respond to new developments.

Eligibility criteria: The design of transactions is likely to be guided by a set of eligibility criteria that ensure results are delivered according to good practice. The GCF will have to define its standards on, for example, social issues (such as treatment of indigenous peoples), local environmental issues (such as biodiversity), economic impacts (such as state aid) and integrity (for example, corruption). There may even be certain types of GHG reductions that are deemed ineligible a priori (for example, related to industrial gases).

Unit of measurement: What the GCF is ultimately interested in is a reduction in the absolute level of greenhouse gas emissions. An obvious way to measure results is therefore in terms of absolute emission levels expressed in tonnes of $\mathrm{CO}_{2}$-equivalent. Some countries may prefer a relative metric that expresses emissions relative to economic output, as this imposes fewer constraints on growth (but poses higher risks in terms of meeting the global climate objective). Another alternative is to express results in a proxy measure, such as hectares of forests or $\mathrm{kWh}$ of low-carbon energy. The former was, for example, used in the Amazon Fund (see below), which applies a simple calculation to estimate emission reductions based on hectares of avoided deforestation.

Reference level: The reference level defines the benchmark against which results are measured. It reflects the emissions pathway that the counterparty is willing to adopt without QPP-support and/or the contribution it will make to the mitigation burden. There are three broad ways to set the reference level (although practical approaches may combine elements of each). The first is to negotiate deal-bydeal, in which case the reference level primarily reflects the bargaining power and negotiating skills of the counterparty. The second way is to set reference levels based on agreed criteria for global burden sharing. An example of such a formulaic approach is found in Wheeler (2012). The third way is to set the reference level according to a counterfactual 'without transaction' situation. In this case the reference level reflects what would have happened in the absence of QPP-support, the counterparty does not contribute to the cost burden, and, subject to measurement error, it is compensated fully for any extra costs. This is the incremental cost philosophy of the GEF and the additionality approach of the CDM (Müller 2009).

Measuring, reporting and verification: $M R V$ is an important aspect of defining and verifying a result for which payment is made. The broad topic of MRV for all emission reduction programmes covers many issues that would also be generically applicable to QPPs (Mucci 2012). For a micro-level transaction, a QPP would be able to piggyback on verification systems for tradable credits under the $\mathrm{CDM}$ or local carbon markets (or systems that might be developed for sectoral crediting). However, 
project-by-project validation and verification tends to be administratively intensive. In the case of the macro model, the GCF would need to verify performance levels. This would be a simpler process than current CDM verification, as there is no need to validate baselines and additionality, but just to assess the annual performance level in relation to the agreed reference level set.

\subsubsection{Price (Compensation) Setting}

It is possible to support a mitigation activity without explicitly specifying a price for emission reductions. However, since QPP is explicitly about quantity- and performance-based support, price setting is essential. We distinguish five possible price setting mechanisms:

Deal-by-deal negotiations: Negotiating the compensation level for transactions deal-by-deal has the advantage of flexibility and allows responses to be made to individual circumstances. The disadvantage is that individual negotiations without an external benchmark could lead to disparities in outcomes that are deemed unfair. Moreover, if the number of QPP transactions is large individual negotiations may be unduly burdensome.

Market-based pricing: Emission reductions have had an increasingly observable value in the international carbon market. It is unlikely that this price is an accurate reflection of either the social cost of climate change or of the economic cost of meeting future carbon targets (Dietz and Fankhauser, 2010). Nevertheless, observed market prices may be a useful benchmark against which GCF payments can be set. This is particularly the case if counterparties have the choice between accepting a QPP or monetizing the same emissions savings on the international carbon market. If the GCF were to adopt some form of market-based pricing, it would make sense to link the price not just to one market but to a basket of emission-reduction commodities (combining, for example, European, Australian, and emerging regional carbon markets).

Cost-based pricing: Support based on the incremental cost of an activity has a long tradition in international environmental finance. It goes back to the Montreal Protocol of 1987 and is the basic principle behind GEF funding. However, calculating the full cost of one course of action over another accurately is extremely difficult and entails high administrative costs. This issue may be particularly evident with QPP transactions, which may include wider, less tangible policy initiatives (such as a feed-in tariff) rather than the specific investments for which measures of incremental costs were designed.

Auctioning: In a situation where transactions and/or counterparties are selected competitively through an auction, the price level may also be determined through that auction. It is likely that the selection of transactions and counterparties under auctions would be based on price.

Top-down pricing: The GCF may decide to set its own administrative price. For example, it could define an emission reduction ambition for the QPP window (derived, maybe, from the $2^{\circ} \mathrm{C}$ target and the emissions budgets this implies), and distribute the funds available under QPP evenly over these tonnes. Given the potential prominence of QPP, the GCF would then de facto become an international price setter. The risk with this approach is that an arbitrarily set administrative price may not be consistent with either the mitigation costs faced by host countries or the market price for carbon observed elsewhere.

\subsubsection{Setting the transaction quantity}

Agreement also has to be reached on the level of results, or quantity of output, that the transaction will cover. The transaction quantity is calculated as the difference between an agreed reference level of 
activities (see above) and the amount the GCF is willing or able to purchase. It could be defined in the following ways:

Based on actual performance: Perhaps the most straightforward way of determining the transaction quantity would be to simply set it based on actual (monitored and verified) performance - such as actual emissions levels. The disadvantage of this approach is that it creates considerable uncertainty for both the counterparty (in terms of payment streams) and the GCF (in terms of missing its, firm or indicative, emission reduction objectives under QPP).

Restricted by an agreed delivery cap: If there is concern about the high potential liabilities of the GCF in the case that transactions perform above expectations, transaction payments may be capped. That is, payments would not exceed a certain level, even if the delivered results exceed expectations.

Supported by an agreed delivery floor: If the main concern for QPP is underperformance, and the risk that QPP transactions may not deliver the emission reductions required, transactions may be subject to a minimum delivery obligation. Counterparties would be subject to a penalty if they underperform. Agreement on a minimum performance level may be hard to reach. It would require a tight, contractual agreement between the GCF and its counterparties and a fairly commercial interpretation of QPP.

\subsection{Further design questions}

While a QPP transaction is fundamentally defined by the four elements discussed above counterparty, result, price, and quantity - there are other features that define the nature and attractiveness of a transaction to counterparties. Chiefly they have to do with contractual arrangements, the allocation of risks between parties, and the interaction of QPP transactions with other emission-reduction mechanisms.

\subsubsection{Contractual tie-in}

The emphasis on large-scale change and paradigm shifts means that QPP transactions are likely to be long-term programmes that require some patience before results materialize. An important question, then, is at what point the parameters of a QPP transaction should be agreed and to what extent they have to be determined in a formal agreement ex ante.

Forward agreements: Structuring transactions ex ante as a forward agreement has the advantage of providing contractual certainty to both the GCF and its counterparty, but it may also reduce the flexibility of either party to respond to external developments. Such an agreement would stipulate, right from the start, what type of payment would be made, at what point in time, against what kind of result. In this way, counterparties obtain sufficient assurances about GCF-related revenues to justify their upfront investment. The GCF, in turn, can be more comfortable about the prospects for emission reductions and a long-term paradigm shift.

Spot transactions: It is conceivable to think of QPP designs that do not require an ex ante agreement. Recipient NFEs could choose to reduce emissions unilaterally with a view of negotiating compensation payments as spot transactions ex post (as has been the case of the Amazon Fund), or funders can unilaterally offer payments for performance by setting their own reference levels and putting cash on the table (as is the case in the proposal for emission reduction pathways developed by the Center for Global Development (CGD)). This structure could be attractive for programmes that do not entail large upfront risks, or to counterparties that expect an increase in future compensation. However, emission reductions are a public good, and those unwilling to pay can still enjoy the 
benefits. Unilateral action, therefore, runs the risk of not being properly rewarded, particularly if the GCF has a certain amount of market power.

\subsubsection{Risk allocation}

The basic principle of QPP is that payments are performance-based, against delivery. This may suggest that most, if not all, risks related to a transaction would be borne by the counterparty. If emission reductions do not materialize, there is no payment. Yet the risk distribution is unlikely to be as one-sided as that. Different design structures are available to adjust the ultimate risk profile. Among the key risks are:

Counterparty risk: We have seen above that most QPP transactions are long-term programmes that will often require an upfront agreement. Such long-term relationships are difficult to manage, with each side having to trust the other to deliver, particularly if the upfront agreement is loose. There will have to be the right balance between commitment and flexibility - for example, in the face of technology breakthroughs or political developments (such as a change in host government). This can be reflected in the length of the agreement, the number of review points, or the payment profile.

Price risk: Over the course of a long-term agreement, the cost and value of emission reductions will change. For example, between 2011 and 2013 the value of Certified Emission Reductions (CERs) from the CDM has fluctuated between more than US\$16 and less than US\$2. Although QPP transactions have their own price, such fluctuations in price of other emission-reduction instruments matter. Price risks may be allocated in different ways. Under a fixed-price agreement (where the unit price is agreed up front) the GCF would absorb the impact of all future price fluctuations. If payment is indexed to a benchmark price (to a basket of carbon market schemes, for example) it is the counterparty that assumes price risk. Asymmetric risk allocations are also possible. If counterparties have a put on the GCF (see below), they retain upside risk but pass on downside risk to the GCF.

Exogenous risks (such as technology, climate, macroeconomic situation, force majeure): Emissions may fluctuate, or transactions fail, due to external factors outside the control of counterparties, host governments, or the GCF: New technologies, such as carbon capture and storage, may fail to deliver as planned; Weather extremes may result in forest fires in summer or exceptionally high heating emissions in winter; Emissions may fluctuate with the business cycle (Doda, 2012); Countries in less stable regions may be affected by war or civil unrest among neighbours. The GCF will have to determine to what extent it is willing to share some of these risks. Similarly, defining results relative to output $\left(\mathrm{tCO}_{2}\right.$ per $\mathrm{kWh}$, for example) rather than in absolute terms $\left(\mathrm{tCO}_{2}\right)$ would transfer macroeconomic risks from the counterparty to the GCF (which is interested primarily in absolute emission reductions). The GCF may be able to spread these risks over its full transaction portfolio. Alternatively, it may work with the private sector, or organizations like the Multilateral Investment Guarantee Agency (MIGA), to offer insurance cover to counterparties for particular risks.

\subsubsection{Interaction with other mechanisms}

QPPs would only be one of several mechanisms used to promote decarbonization in developing countries. There would be alternative programmes both within the GCF and offered by other institutions such as the GEF, the multilateral development banks, the UN, and bilateral agencies. The question is how they would interact. In the case of different performance-based programmes (such as QPP and the carbon market), there is the particular danger of results being double-counted. There are three generic ways in which competing instruments may be delineated:

Complements: Host governments may find it beneficial to combine QPP with less quantity-oriented programmes that can build delivery capacity or remove barriers. In addition to climate change projects 
(such as GEF technical assistance) this may also include development finance (used, for example, to improve access to energy) and other environmental funding (for example, for the protection of forest biodiversity). Agreement will have to be reached on whether such parallel efforts are factored into (that is, help host governments to achieve) the reference level, or subsidize QPP delivery.

Substitutes: Unlike technical assistance, different Quantity Performance-based programmes are intrinsically substitutes. The main QP alternative to QPP is likely to be international carbon trading, together with other private sector programmes (such as QPF, see Section 1.2). Host governments will have to choose ex ante between them. It is not a choice between the public and private sector. Even under a QPP, private delivery is crucial, but firms are incentivized through the regulatory framework that underpins a QPP. For example, renewable energy producers may benefit from a feed-in tariff put in place to ensure QPP delivery, rather than from the sale of carbon credits. Nor is the choice categorical. Joint programmes (where several organizations agree to share the quantified results) are conceivable and in the case of large, risky transactions they are even desirable. Host governments may also choose different mechanisms for different sectors or regions - for example, a QPP on forestry, and carbon credits for energy. However, the delineation will have to be strictly monitored and clearly enforced.

Decision after delivery: Another way would be to let host governments choose between QPP and an alternative mechanism ex post, upon delivery. They may still enter into an enhanced QPP up front, but maintain the option of monetizing results under a different mechanism, for example by selling carbon credits. This is essentially a put option. The QPP would offer a revenue floor, while allowing counterparties to seek upside on the carbon market. This has obvious attractions to hosts, but could entail considerable administrative complications. MRV requirements under the different mechanisms would have to be fully aligned in order to allow for a smooth switchover. 


\section{Early Experiments and Conceptualizations}

Part 3 outlines the design of a number of existing and proposed Quantity Performance instruments for climate finance both for the public and the private sector - Quantity Performance Payments (QPP) and Quantity Performance Finance (QPF) instruments in the terminology introduced in Section 1.2. Each of these initiatives comprises a deal (or deals) between a funder and a recipient counterparty to release payments for achieving quantitative results related to emission reductions, subject to monitoring and verification. Some also package this with other forms of funding and support - such as concessional loans, technical advice, and capacity building grants; here, however, we focus particularly on the QP aspect.

We first consider a set of initiatives that take a QPP approach; that is they are transfers from an international funder to a national funder, tied to the achievement of quantitative 'macro level' results, namely:

- Norway's International Forest Climate Initiative (IFCI), which is focused on reduced emissions from deforestation and forest degradation (REDD+).

- The Energy+ partnership, which is seeking to develop a system of performance-based funding for progress in relation to clean energy development, energy efficiency, and energy access.

- The Center for Global Development, a leading proponent of cash-on-delivery systems for development aid, which has developed a set of tools and proposals for applying these principles to climate finance, in support of emerging REDD+ and Energy+ initiatives. It proposes a system of payments for accelerated transition pathways.

While significant attention has been paid in an earlier OIES publication (Müller et al., 2012) to the development of international funding mechanisms that provide more direct output-based QPF to service providers, we believe it would be useful to list some additional examples in this Paper:

- Deutsche Bank has been developing the Global Energy Transfer Feed-in Tariffs Program (GET FiT). This is a proposal to support both renewable energy scale-up and energy access, through the creation of new international public-private partnerships combining public money for renewable energy incentives, risk mitigation strategies (such as international guarantees and insurance), and coordinated technical assistance to address non-financial barriers and create an enabling environment for project development (Deutsche Bank, 2011). Another initiative, which has explored the adoption of a similar approach, is the South African Renewables Initiative (Zadek, Forstater, Ritchkin, Fakir, Kornik, and Haas, 2010).

- There have been discussions about using Certified Emission Reductions as a measurement unit for public climate results-based finance transactions, drawing on existing certification systems developed for the CDM (Müller et al., 2012).

- Climate Change Capital has proposed an Emission Reduction Underwriting Mechanism (ERUM) which would act as an international advanced market commitment to purchasing emission reductions as a commodity (Edwards, 2011). This option has also been explored by the multi-donor investment group Private Infrastructure Development Group (PIDG) in developing its Green Africa Power initiative. Most recently, the idea has been introduced into the UN climate change negotiations in the form of proposal for a CDM Stabilization Fund. 


\subsection{Quantity Performance Payments}

\subsubsection{The Norwegian International Forest Climate Initiative (NICFI)}

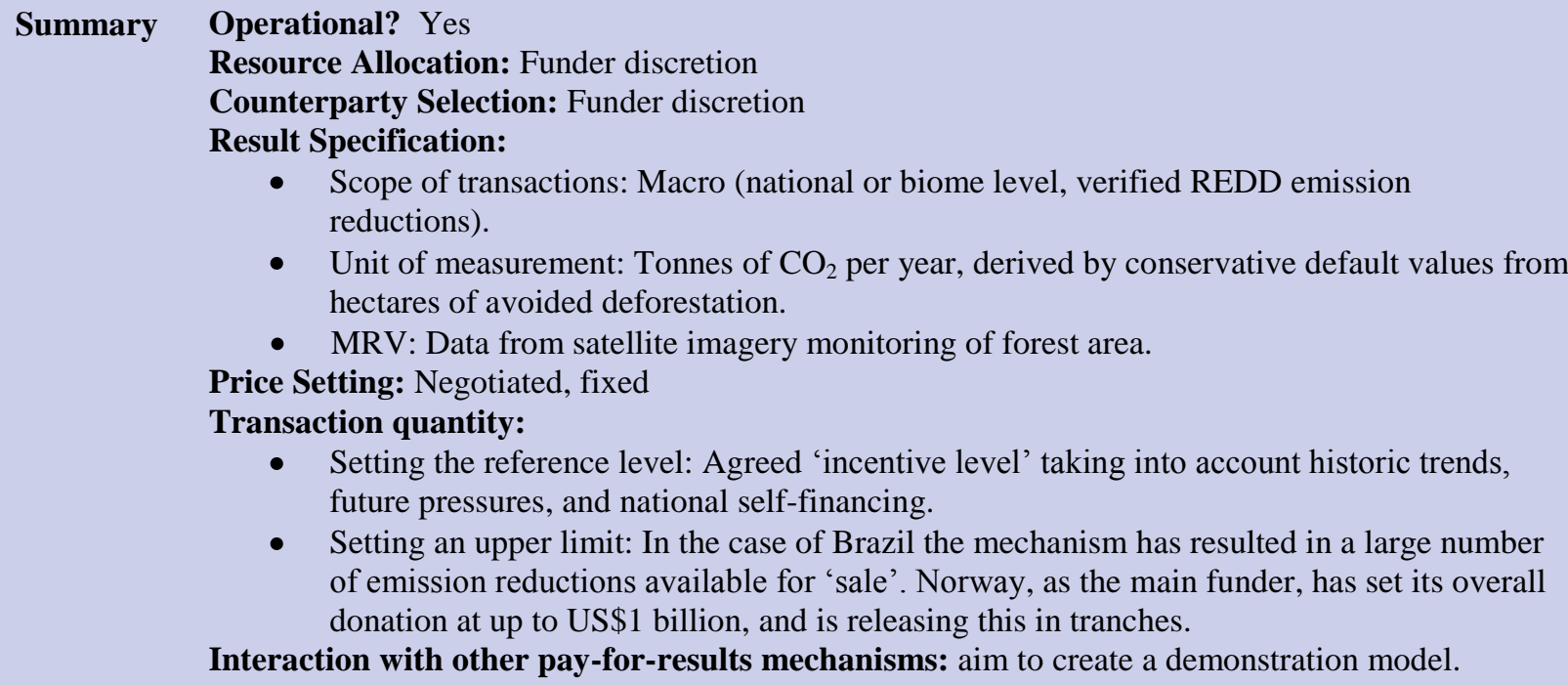

- Unit of measurement: Tonnes of $\mathrm{CO}_{2}$ per year, derived by conservative default values from hectares of avoided deforestation.

- $\quad$ MRV: Data from satellite imagery monitoring of forest area.

Price Setting: Negotiated, fixed

Transaction quantity:

- Setting the reference level: Agreed 'incentive level' taking into account historic trends, future pressures, and national self-financing.

- Setting an upper limit: In the case of Brazil the mechanism has resulted in a large number of emission reductions available for 'sale'. Norway, as the main funder, has set its overall donation at up to US\$1 billion, and is releasing this in tranches.

Interaction with other pay-for-results mechanisms: aim to create a demonstration model.

NICFI was launched in December 2007 by the Government of Norway with a pledge of up to three billion Norwegian Kroner (US\$500 million) per year up to 2015 to support emission reduction from deforestation and forest degradation (REDD) in developing countries. In 2012 Norway confirmed its intention to continue, and possibly increase, funding for REDD (Norway Environment Ministry, 2012). Overall the NICFI aims both to support early action to achieve cost-effective and verifiable emission reductions, and to demonstrate how funding for REDD could work in practice, in order to advance the development of an international architecture.

The majority of NICFI's activities are conducted through multilateral channels such as the Congo Basin Forest Fund, the Forest Carbon Partnership Facility (FCPF) and Forest Investment Program (FIP), and the UN REDD Programme (UN-REDD). These, to date, have been largely focused on traditional $e x$ ante funding for capacity building ('redd-iness').

However, Norway argues that:

... ex post payments for verified emission reductions provide the best way to incentivize emission reductions in any sector, including REDD+ (Government of Norway, 2012).

The country has therefore sought to pioneer pay-for-performance funding through its bilateral relationships with Brazil and Guyana; promising up to US\$1 billion to Brazil's Amazon Fund by 2015, and up to US\$185 million to Guyana's REDD+ Investment Fund (GRIF), upon demonstration of reduced deforestation in relation to agreed reference levels each year. Norway has also entered into bilateral agreements with Indonesia and Ethiopia based on the payment-for-performance principle, but these relationships are not yet at a stage where results-based payments have been made.

In the cases of both Brazil and Guyana, funds are 'earned' at the rate of US\$5 per tonne in respect of avoided emissions from deforestation below an agreed reference level (in Guyana this is also adjusted for changes in the level of forest degradation). The national recipient funds are set up as multi-donor funds, although the majority of funding to date has been from Norway.

At present, resource allocation and counterparty selection have taken place through a traditional process of donor decision making (a grant) with the headline 'price per tonne' serving as a mutually 
agreed basis for drawing down on these funds, rather than as a way of allocating resources between countries.

Reference levels - which take into account historic trends, future pressures, and nationally appropriate levels of self-financing - are defined through mutual agreement. Norway calls these 'incentive levels'.

In Brazil - whose historical emissions were close to the global average for developing forest countries - the incentive level is set at the ten-year historic average deforestation rate (updated every five years). Brazil therefore only receives funding if deforestation is below this falling average. However, in Guyana - a high forest cover, low deforestation country - the reference level has been set at at a steady state level. Initially the agreement was that this should be 0.275 per cent forest loss per year; halfway between the global average rate and the national historic rate. However, in order to rapidly dis-incentivize a rising trend, the crediting this baseline has since been amended so that Guyana receives progressively less compensation as the deforestation rate rises above 0.056 per cent, and no compensation if the deforestation rate rises above 0.1 per cent.

The NICFI calculates emission reductions in relation to these reference levels, based on conservative assumptions regarding forest carbon content at $100 \mathrm{tC} / \mathrm{ha}$ (equivalent to $367 \mathrm{tCO}_{2} / \mathrm{ha}$ ).

Based on this approach Norway had, at the end of 2012, allocated results-based payments of approximately US\$600 million to Brazil and approximately US\$115 million to Guyana.

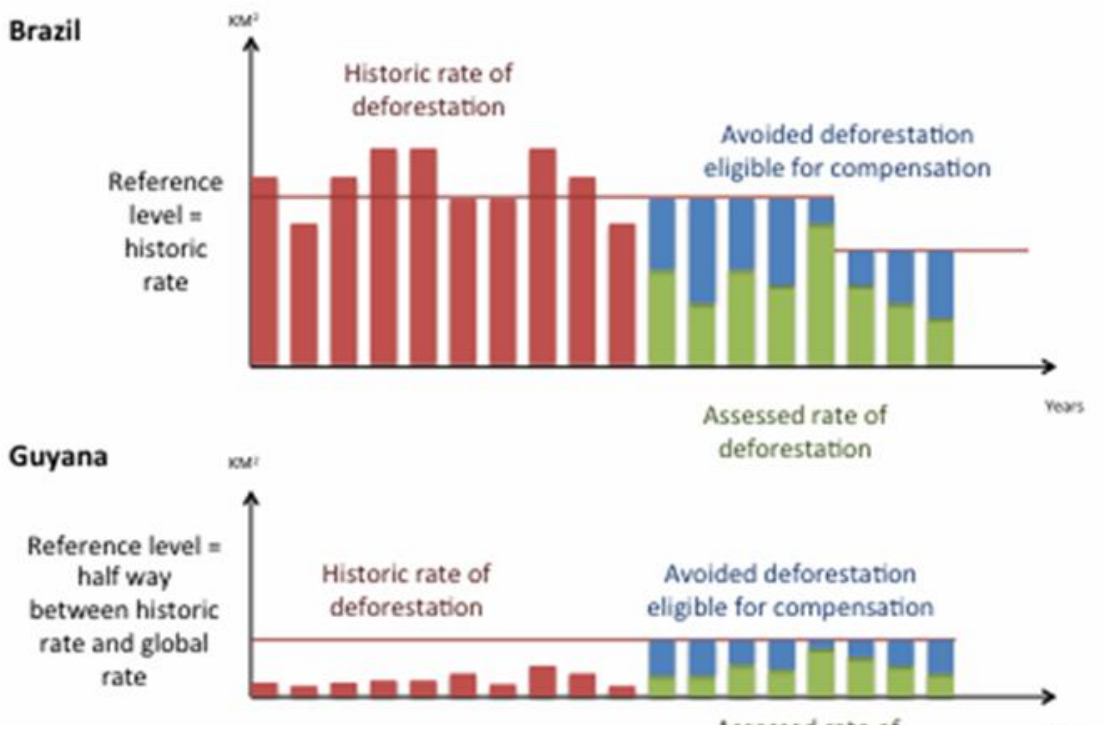

Figure 2. Calculation model for ICFI pay-for-performance in Brazil and Guyana

Source: based on Amazon Fund (2012a ) and World Bank (2012), bars are illustrative.

It should be noted that at present these transactions do not represent the transfer of emission reductions as a commodity, but rather a donation as part of a result-based assistance package (NORAD, 2011). In Brazil, the Amazon Fund issues certificates ('diploma') of recognition for the donation, stating funding drawn down and the carbon equivalent, but these are not tradable tonnes. However, Norway argues that a step-wise approach to setting reference levels and measuring REDD emission reductions may be useful, enabling countries to improve their reference levels and MRV systems over time by incorporating better data, improved methodologies, and where appropriate, additional carbon pools. At an early stage countries may estimate emission reductions in a similar manner to the approaches utilized in Brazil and Guyana, using a conservative factor to calculate the 
carbon content of forests (and thereby changes in emissions) when compensation is being calculated. This approach gives forest countries the incentive to improve their methodologies and data over time, in order to arrive at more accurate estimations of emission reductions and thereby, potentially, to qualify for higher payments (Government of Norway, 2012).

Both in Guyana and Brazil, emission reduction results, calculations, and monitoring data are reported publicly. This enables independent third-party verification to ensure the credibility of results and environmental integrity of the REDD+ regimes. In the case of Guyana, the verification process established has provided important capacity-building functions, by providing concrete input for the improvement of methodology and performance indicators.

In both cases the money is to be spent by the national fund, in support of country strategies for the sustainable development of forest regions. In Brazil, where this is done through a process of projects applying for funding, such projects have to meet criteria of supporting forest conservation and sustainable development objectives, but are not themselves assessed or remunerated on a per tonne basis.

As of mid-2013, spending has lagged the fundraising mechanism, with the Amazon Fund contracting US\$195 million of grant-making and the Guyana Fund committing US\$14 million to activities (Amazon Fund, 2012c; World Bank, 2012). The lack of tension between the overall funding pledged and the rate at which the Amazon Fund is drawing down on the funding means that it is not clear that fund is acting as an effective incentive mechanism, or means of supporting deforestation measures, even while deforestation in Brazil is falling and additional funds are therefore being pledged to the fund each year (Zadek, Forstater, and Polocow, 2010).

In terms of linkage with other types of funding, these pay-for-performance agreements are conceived of as the final stage in a 'phased approach to REDD' in which countries first receive capacity-building support and traditional grants and loans on an ex ante basis, and then graduate to payment-forperformance once they have established adequate MRV systems and a headline of falling deforestation levels.

To date there is no compliance market for REDD, but if one were to emerge, it would become critical that emission reductions assessed at a national scale and rewarded by international public funding were not also sold as project-level emission reductions. Brazil is considering the establishment of a set of nested baselines to distinguish between self-funded emission reductions, those supported by international climate finance, and those available to be sold into compliance markets. Already, however, there is a situation where REDD projects within the Amazon Fund region are producing voluntary carbon credits, creating the potential for double-counting with the Amazon Fund (Zadek et al., 2011).

This challenge is recognized by both the Brazilian and Norwegian governments, but as Norway and other donors currently pay for less than 10 per cent of the emission reductions generated in the Amazon region (according to the very conservative Amazon Fund estimates) this is not a pressing problem. 


\subsubsection{Energy+}

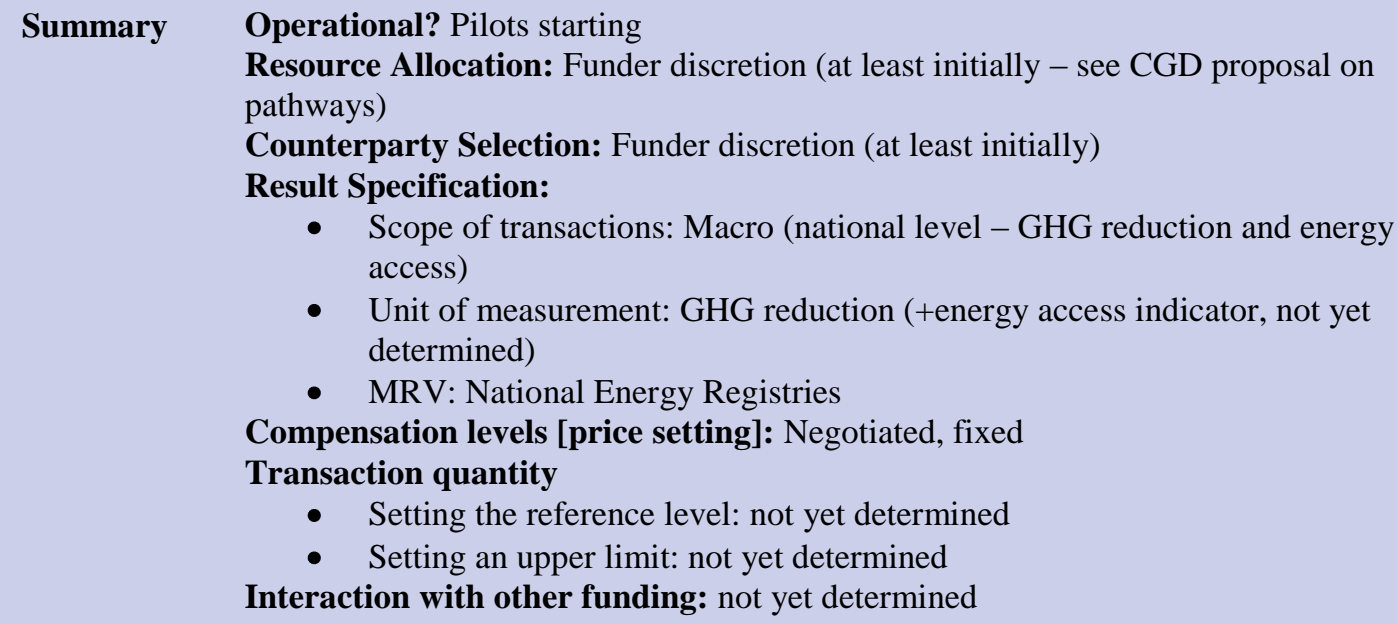

Energy+ was launched in October 2011, as an international partnership led by the Government of Norway. Its aim is to develop a sectoral approach to energy access and reduction of emissions through a payment-by-results system.

Based on the experience of REDD, it envisages a phased approach which offers technical support to countries as they develop their strategy for energy sector transformation. This is then followed by a broad range of financing approaches aimed at leveraging initial investment and supporting capacitybuilding, with countries finally graduating onto a payment-by-results system where international funding is provided for achieved verified results - in terms of increased access to sustainable energy and reduced emissions of GHGs relative to BAU baselines.

Before the Energy+ system for payment-by-results is made operational, it will need an agreed set of metrics, and a basis for establishing reference levels. This will be linked both to emission reduction and energy access. It is hoped to implement the first two phases with initial partners from 2012 to 2015 and to start payment-by-results in 2016 (Norway Foreign Affairs Ministry, 2011).

The initiative envisages that partner countries will establish National Energy Registries (NERs), to ensure transparent verification and communication of the results and to facilitate blended financing from diverse international and domestic financing sources. The NER will be a central portal for information exchange, it will also be a clearinghouse to coordinate programmes, facilitate matchmaking of energy financing, and, importantly, track and monitor results (Energy Plus Partnership, 2012). NERs are conceived of as being compatible with the UNFCCC Registry for matching funding and Nationally Appropriate Mitigation Actions (NAMAs). In itself, such a registry does not constitute a 'national funding entity' but it could form the basis for developing one.

The initiative seeks to support partner countries in implementing their own domestic results-based financing approaches - such as feed-in tariffs and take-off guarantees. However, the design of the initiative is not for a direct pass-through of payment-by-results from the international funding partnership to domestic incentive systems. For example, power-purchase agreements and off take guarantees for renewables are likely to result in different prices for different suppliers dependent on location, technology, and the outcome of individual bidding processes (results-based finance); however, the payment-by-results agreement with international funders will be an overall payment based on macro indicators of access to sustainable energy and GHG emission rates. Blending international and domestic funding flows will be a key role for the National Energy Registry. 


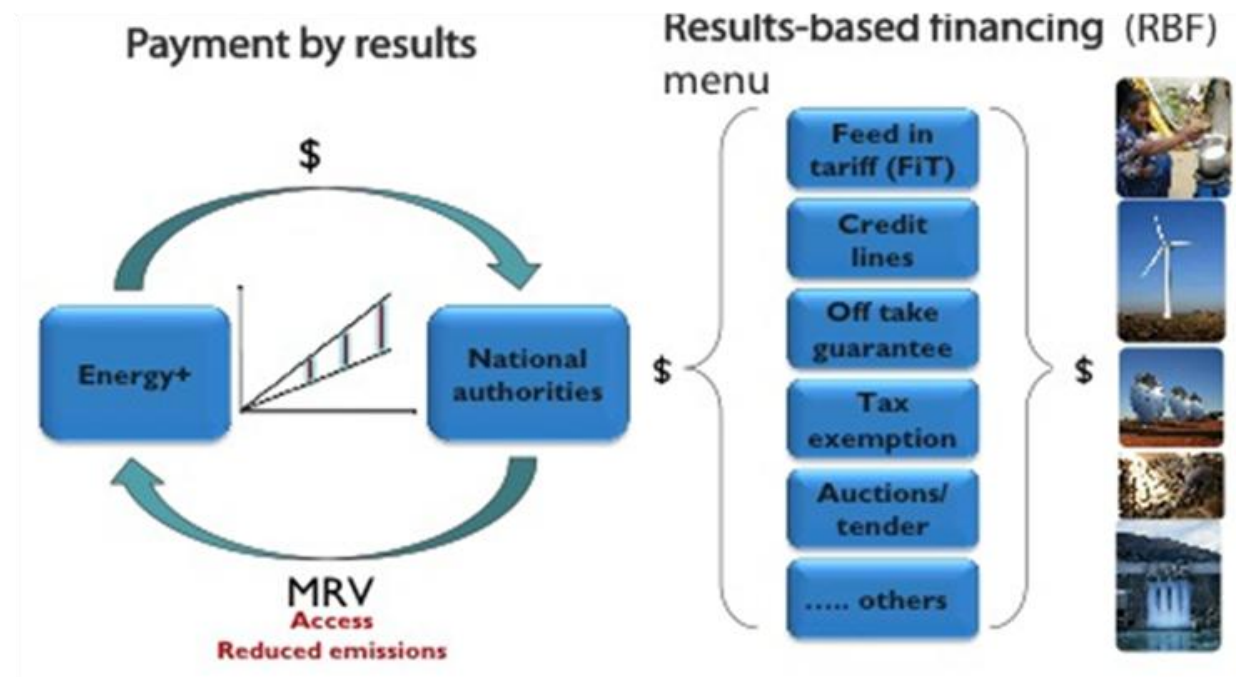

Figure 3. Energy+ two part funding model

Source: Norway Foreign Affairs Ministry (2011).

The initial selection of counterparties for payment-by-results, allocation of resources, setting of prices, and setting of references levels is likely to take place through a partnership approach - by negotiating bilateral mutual agreements (as with Norway's IFCI). However, the designers of Energy+ also recognize that to scale up and to ensure that payment-by-results at country level delivers overall emission reductions globally, a coherent system of reference levels is needed.

The Government of Norway therefore contracted the Center for Global Development to outline a proposal for such a system. This is an early-stage concept which is discussed separately below. 


\title{
3.1.3 Center for Global Development: Rewarding Accelerated Transition Pathways
}

\author{
Summary Operational? Concept only \\ Resource Allocation: based on a formula for entitlement based on dollars per tonne \\ Counterparty Selection: Nationally nominated recipient institution(s) \\ Result Specification: \\ - Scope of transactions: Macro (national or sub-national emission reduction) \\ - Unit of measurement: Energy-related tonnes, and forest-related tonnes (separately) \\ - $\quad$ MRV: Satellite monitoring of forest area and high-level monitoring of energy-related \\ emission intensity of the economy \\ Price Setting: Standard rates \\ Transaction quantity \\ - $\quad$ Setting the reference level: Standardized formula of transition pathways \\ - Setting an upper limit: Negotiated. No built-in system for setting upper limit \\ Interaction with other funding: not yet determined
}

The Center for Global Development has formed a proposal for an international system of payment for emission-reduction results.

The proposal takes a sectoral approach to the tools used as performance measures: for forests using the Center's Forest Country Performance Rating (FCPR), and for energy using the Energy Country Performance Rating (ECPR) (Wheeler, 2012; Wheeler et al., 2012). The two systems would operate independently - one measuring emission reduction in relation to avoided deforestation, and the other in relation to GHG emissions from the energy sector.

In any country there will be a range of different emission-reduction opportunities such as - for energy-related emissions - energy efficiency, wind, solar, hydro, biomass, on-grid/off-grid, and eventually CCS. Each of these opportunities will come with a different price tag. However, this model offers single sectoral prices as input to support governments in planning integrated sectoral strategy. Such strategy not only includes project investments, but also public infrastructure and the governance decisions needed to accelerate green economic transitions.

The proposal is to set a stable 'sectoral price' to reward developing countries for achieving performance above established reference levels. To establish the price and quantity of emission reductions, a series of 'sectoral transition pathways' are calculated for each country, using standardized formulae.

Expected sectoral pathways are based on the observation that a county's rate of, say, deforestation, declines as its per capita income rises, while the energy intensity of its economy tends to fall. Expected sectoral pathways are calculated for each country based on projections of population size and economic growth, as well as factors such as relative abundance of different fuels and natural resources, prevailing temperatures, and spatial distributions of population and economic activity in each country.

A second more ambitious set of pathways is calculated, which accelerates this transition to the point where, say, zero forest clearing is achieved by 2025 ('the REDD+ pathway') and there is a 95 per cent reduction in global emissions between 2000 and 2050 ('the Energy+ pathway').

The developers of this model say that sectoral prices which offer credible compensation for conservation and for energy emission reduction, and which remain stable for a substantial period of time, should be set. In practice, the price per tonne which is offered would need to be calculated by dividing the budget available over a particular timeframe by the number of tonnes that need to be reduced, in order for it to shift to the ambitious pathway. 
The fund also needs to establish what to do when countries are performing beyond the level required by the ambitious pathway. One approach, which would limit the fund's payment liabilities, would be only to pay out up to the ambitious level. This could be secured through a mechanism similar to the advance market commitment on vaccines, in which funders enter into an agreement, enforceable by law, to make multiyear payments of uncertain size and duration (though with a known upper limit).

Another approach, proposed by the model's developers, which would give a stronger incentive, would be to offer a higher level of payment-for-performance beyond the ambitious pathway. This would open up the fund to more uncertain liabilities. They do not specify how this could be secured, but one potential approach could be through insurance.

While this mechanism does not offer a competitive project-by-project or country-by-country pricefinding mechanism, it does offer a global mechanism which generates, and can respond to, a signal which demonstrates whether the overall goal of emission-reduction is being met, and therefore whether the price per tonne it offers in the next period should be increased or decreased. A single price means that countries will earn rents for making easy and cheap emission reductions, and in other cases will need to mobilize a blend of different resources to make more expensive changes. The role of National Funding Entities therefore is to play an active role in stewarding these resources and in blending funding sources to support a national strategy for green economic growth.

The Energy Country Performance Rating was developed specifically to support the Energy+ Initiative. However, the Center for Global Development notes that it could be implemented without entering into individual partnerships; simply by offering universal payments by results, which are triggered by the external performance rating. It can also be used as a public rating for Annex I countries, without offering funding. While this model does not depend on carbon markets, there would need to be a mechanism for ensuring that any emission reductions sold into compliance markets are not double counted as part of a national performance rating, for the purpose of drawing down on public payments. 


\subsection{Quantity Performance Finance}

\subsubsection{Global Energy Transfer Feed-in Tariffs Program (GET FiT)}

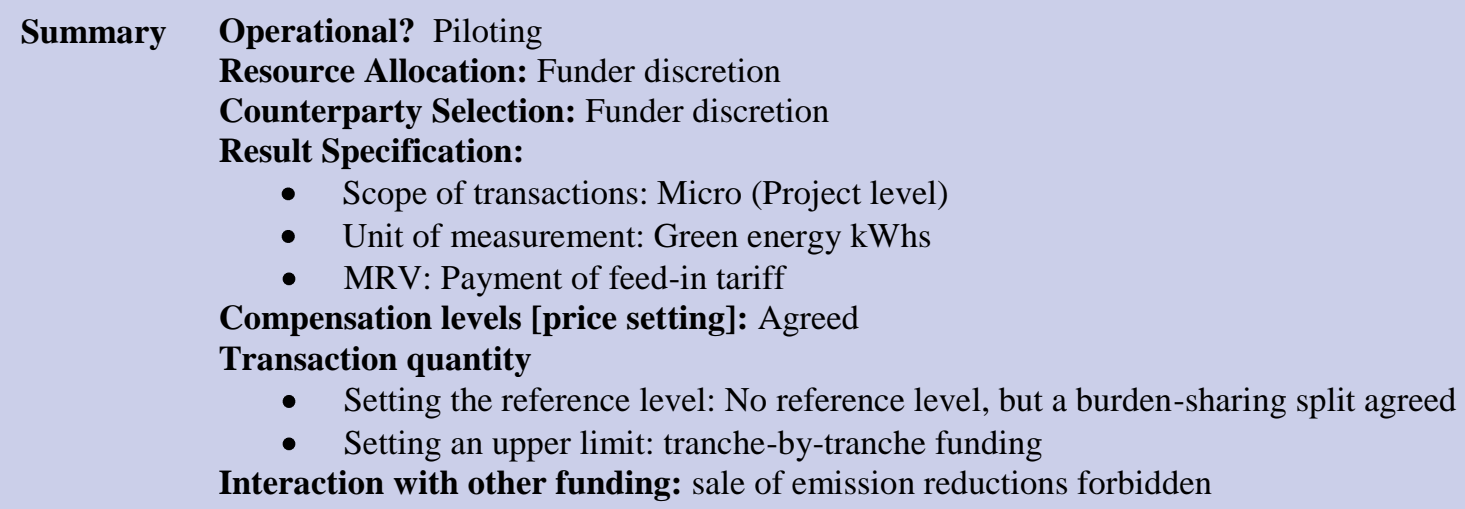

GET FiT is a concept designed to drive renewable energy investment, which has been developed by Deutsche Bank Climate Change Advisors. It aims to support and incentivize countries to develop policies which provide the 'Transparency, Longevity, Certainty and Consistency' (TLC) needed to mobilize private investment in renewable energy (Kreibehl, 2012).

It is unusual in that it is a model for providing an international stream of results-based finance (in other words, funding linked directly to the provision of outputs) rather than payment-by-results, as has been the case in the initiatives covered in the previous Section.

At present it is being developed on a pilot basis, so funding is agreed tranche by tranche, to provide top-up funding to enable a country to develop an agreed amount of renewable energy capacity.

At its core is an agreement to provide funds to top up domestic electricity tariffs to cover the cost of renewables, together with the facilitation of a partial risk-guarantee facility to cover the whole of the power-purchase agreement, and a separate a private equity/debt facility to catalyse early investment. This combination of cost-lowering and cost-covering measures is being trialled in a pilot being established with the government of Uganda.

Paying for performance on a per $\mathrm{kWh}$ basis has the advantage of shifting risk onto the Renewable Energy (RE) developer who will only be able to access the subsidy once a fully operational plant is in place. However, a key challenge is the difficulty of matching the disbursement of international public funding effectively and efficiently to the timescale required for long-lived investments.

The model being developed and trialled by GET FiT is one where an agreement based on a notional international contribution towards a viable feed-in tariff (closing the gap between the existing tariff and the levelized cost of producing renewable energy) is negotiated. In practice, the payment schedule for this international subsidy is then rolled up into the early years of the plant's operation, with a premium paid when the plant first begins to operate and on its output in the first few years.

The actual gap will be different across individual RE projects. However, where the feed-in tariff is targeting a large number of small projects, GET FiT proposes, for simplicity, to offer a standard per$\mathrm{kWh}$ premium for each technology group. For larger power-purchase agreements the project developer is likely to negotiate a tailor-made tariff, and an international subsidy premium payment could be included as part of that. 
The details of the incremental subsidy, the technologies covered, disbursement modality, and interface with respective governments and regulators will be customized for each country, with a case-by-case negotiation of the burden-sharing split between national stakeholders and international donors.

The aim of the country pilots will be to enable the development of a limited 'first mover' portfolio of renewable generation. The aim is for a first critical mass of renewables projects to be used to accelerate learning curves, deepen and widen local renewables industries, and encourage costreflective tariff setting by governments.

However, in relation to some countries and technologies, it is likely that an incremental cost gap will remain, which cannot be bridged through such 'kickstarter' investments. The programme developers reflect that in the long term FiTs are likely to need a blend of hybrid and innovative sources of funding, public and private, international and domestic, as they scale up. One possibility they see is that the funding mechanism they are demonstrating could for the basis of a sectoral approach to funding under a NAMA crediting or NAMA funding scheme (such as a GCF Quantity Performance funding window).

The programme does not envisage any direct link to the carbon markets within the current CDM, and prohibits FiT Premium Payments being received by projects under the mechanism of selling carbon credits in the official market.

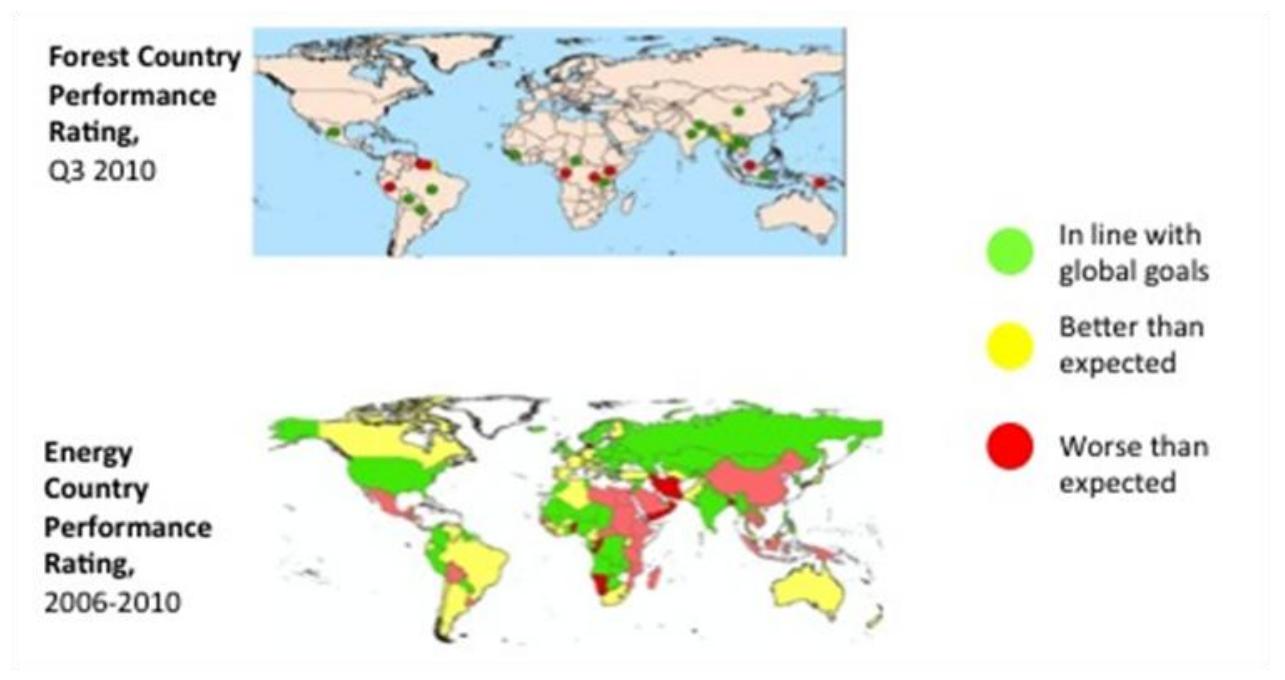

Figure 4. 'Traffic light' Rating countries on accelerated transition pathways for energy and forest performance

Sources: Wheeler (2012) and Wheeler et al. (2012). 


\subsubsection{A CDM Stabilization/Capacity Fund}

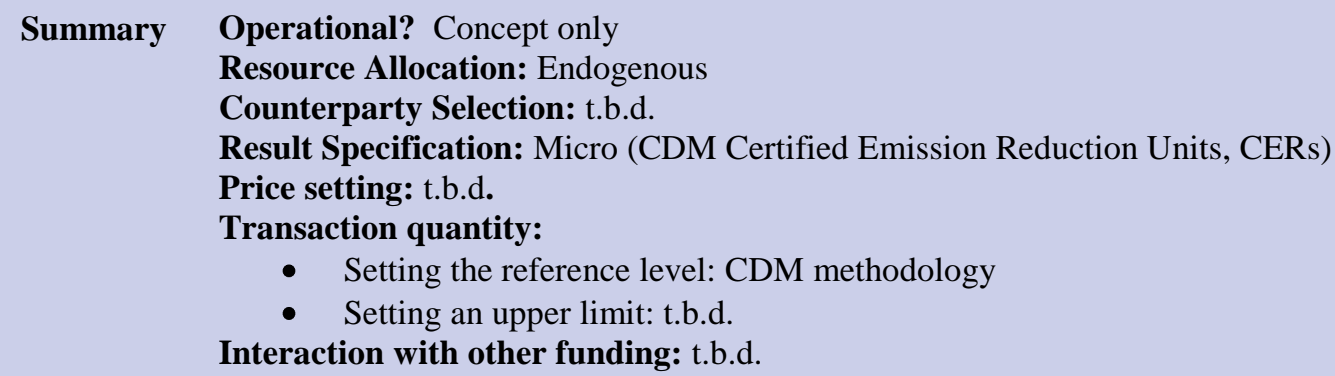

On 28 November 2012, in the morning session of the CMP (the governing body of the Kyoto Protocol), the Indian delegation at the Doha Climate Change Conference drew the attention of the Parties to the fact that CER prices had plummeted because of a collapse of demand, and that:

... there is therefore a need to create a Stabilization Fund under the Kyoto Protocol which should help stabilize the CER prices. If we want the CDM to continue to function as an effective tool of sustainable development as well as cost effective emissions reduction, this is an urgent necessity.

Later the same day, a Ministerial Dialogue concerning the role of market mechanisms under the UNFCCC was held - based on the recommendations put forward in the Final Report (CDM, 2012) of the High-Level Panel on the CDM Policy Dialogue (Panel). ${ }^{13}$ The Dialogue was opened by Joan Macnaughton, vice-chair of the Panel, who in her intervention mentioned the Panel recommendation regarding the establishment of a Stabilization Fund.

The Report itself mentions the idea as part of its Executive Summary recommendations on addressing the immediate crisis as a matter of urgency:

1.3 Investigate the establishment of a new fund and/or enable existing or emerging funds to purchase and to cancel part of the current overhang of CERs. National governments could be invited to meet part of their commitments to international carbon finance through contributions to this fund. The CDM Executive Board could be authorized to use a portion of the financial reserves of the CDM to establish and commence the operations of this fund.

1.4 Consider the establishment of an institution to serve as a de facto reserve bank for CERs, charged with stabilizing the market. CDM (2012)

There is not much more in the body of the Report on this idea, but there is a Policy Brief on 'Sustaining the Global Carbon Market: Urgent Action and Reform of the CDM Required' by Macnaughton (available on request from the author) which provides some more detail.

Macnaughton - under the heading 'An idea whose time has come - a CDM reserve facility' - points out that in order to stabilize the price of CERs, additional demand should be provided through what she calls 'cancellation facilities' for buying and cancelling credits in the market; ${ }^{14}$ and/or by building up a CER reserve with a view to assisting compliance buyers in the longer term. As concerns the design of such facilities, Macnaughton proposes two models:

(i) The facility could invest in CDM projects and programmes, with a view to both maintaining capacity and providing low-cost mitigation, while cancelling wholly or part of the future CER stream. CDM then becomes one metric of mitigation related finance and would/should be counted for as contribution to the public commitment to scale up climate finance undertaken in

\footnotetext{
${ }^{13}$ High-Level Panel on the CDM Policy Dialogue.

14 The idea of supporting developing country mitigation activities through purchasing and cancelling/retiring CERs as part of developed country funding obligations was expressed by one of the Panel members in a policy note on how to use the CDM in the Bali Action Plan: Müller and Ghosh (2008).
} 
Copenhagen and Cancun. In essence, this replicates the success of advanced market commitments undertaken in other global public good arenas, such as vaccine development.

(ii) In another design, the facility could buy CERs for a set period of time - in order to sustain a viable predetermined price - on behalf of contributors who would then be able to exercise an option to use them towards compliance with their own targets or commitments under international or domestic climate policy. Such a facility could then recycle the revenues obtained into further mitigation goals.

She also envisages that sources:

... should not be limited to public funding, given the prevailing situation in many countries. Innovative sources of funding - such as tax deductions on inheritance tax and other potential options without direct impact on country budgets - should be pursued. Raising private and notfor-profit capital should also be a priority.

Her Policy Brief ends with some considerations regarding governance:

A simple, transparent and effective governance structure is required. ... If possible, any governance should make use of existing institutions and arrangements. The World Bank, given its role as secretariat for the Partnership for Market Readiness and other post-2012 market-related capacity building initiatives, is one option to explore. ... Any such facility should coordinate action with the GCF, in particular through its mitigation window for payment for verified results, showcasing the possible use of reformed CDM as a certification process for such results-based finance efforts.

An alternative to this would be to use the Private Sector Facility (PSF) of the Green Climate Fund itself as such a CDM reserve facility. Indeed, this would not only fit perfectly with the ideas put forward in Ghosh et al. (2012) on the use of QP Finance Instruments, but it would actually enable the PSF to hit the ground running with respect to QPF.

As it happens, following the CDM Policy Dialogue recommendations, the UNFCCC Secretariat very recently commissioned a study (Vivid Economics 2013b) with the aim of investigating, among other things, the market impacts of different fund design options. More precisely, the study assumes that the ultimate objectives to be achieved are:

- to provide an appropriate forward-looking price signal for new mitigation action in non Annex 1 countries;

- to ensure the sustainability of existing projects (and their emission reductions and sustainable development impacts) that may be threatened by low prices;

- to maintain developing country carbon market infrastructure;

and that the way to achieve this is to stabilize the (forward-looking) CER price though what is referred to as a 'CDM Capacity Fund'.

The finding that the capitalization required to achieve the aim of stabilizing the CER price depends significantly on the particular design of the proposed fund is interesting in the present circumstances. A number of design parameters are considered in the study.

In a first instance, the study differentiates between a fund purchasing existing CERs, and one purchasing CERs from new projects. In the case of the former, the study concludes that the same price stabilization result could be achieved with significantly less cost if, rather than simply buying CERs at the market rate, the Fund were able pay different prices for different (types of) credits, which, it is suggested, could be achieved by the Fund running an auction with project developers bidding at the 
price they would need to receive for issuing CERs. ${ }^{15}$ The study also envisages that such an auction could be designed so as to allow objectives other than cost minimization. In addition, if a fund only decided to purchase certain types of credits, or applied different auction rules for credits from different types of project, then, it is claimed, a fund of a given size could achieve a greater price effect for credits according to the project from which they came.

As regards the purchase of 'future' CERs, it is mentioned that for credits from yet-to-be registered projects the Fund is likely to be the only material source of demand in the next few years, and thus the Fund's purchasing would determine the market clearing price and quantities. The study considers three basic design options:

(1) a 'basic fund': the fund commits to use a certain amount of resources to purchase as many credits as possible at the prevailing market price(s),

(2) a 'price floor' fund: the fund commits to purchase an (unknown number of) credits at a certain minimum floor price;

(3) a 'quantity commitment' fund: the fund commits to purchase a certain number of credits at an (unknown) price(s).

All could be restricted to credits from certain project types ('eligible credits'). Moreover (2) and (3) could be combined with a maximum spending commitment, which is by definition the case for option (1).

\subsection{Conclusions}

The examples demonstrate that many of the design options and issues identified in Part 2 have already been explored in practice. But it also emerges clearly that none of the examined models in operation offers a tried-and-tested QPP instrument ready-made for adoption by the GCF. A number of conclusions can be drawn.

\subsubsection{General points}

Both micro and macro-level frameworks have been implemented or at least conceptualized. The Amazon Fund approach of national reference levels and performance measures can be seen as an early pilot for the macro approach, further developed in the CGD pathways model, while the GET FiT approach of project-by-project funding provides useful insights into the micro approach also advocated in the CDM Fund approach.

The micro approach has the attraction of delivering directly attributable emission reductions, insofar as the certification system is able to identify 'additional reductions'. As the analysis carried out by the UNFCCC Secretariat highlights (Vivid Economics 2013b), linking funding to a certified commodity allows for both market pricing and reverse auctioning to be used, thus supporting the goal of economic efficiency (but increasing the administrative costs by requiring project-by-project verification rather than a single macro indicator).

The examples of the macro approach do not tie the international funding to particular projects or programmes, but rather to the results achieved and measured at a national level. This is administratively simpler, leaving the question of the economic efficiency of allocating funding to particular activities or projects out of the mechanism altogether (delegating it to national funding entities).

\footnotetext{
${ }^{15}$ Projects registered with the CDM can be used to generate CERs, but the decision as to when the CERs are to be issued (e.g. to be put up for sale) is with whoever has the right to issue (usually the project owner), and it will incur some issuance costs (such as verification of the reductions underpinning the issuance).
} 


\subsubsection{Setting the transaction parameters and resource allocation}

Definitions of price, quantity, and results in the presented existing models are quite soft. Although payment is, in principle, against results, arrangements are much closer to a traditional aid agreement than to a commercial contract. At the time of writing, each of the three operational instruments that were discussed (the Amazon Fund, Energy+, and GET FiT) relied on discretionary counterparty selection and price-setting procedures, which were effectively grant allocations, disbursed by way of a pay-for-performance mechanism. As such, they do not involve a mechanism for price-finding or for determining resource allocation between countries. Rather, their 'headline' unit price figures (\$/tonnes) act as means to determine the schedule and amounts of money disbursed over time, within a pre-agreed overall allocation of funding. The decision to allocate resources in each case is determined not by looking at the 'price' (the cost per tonne), but through more traditional considerations, with 'value' determined at an overall project or programme level, in negotiating a mutually acceptable international funding package. ${ }^{16}$ As the cases of Norway's dealings with Brazil and Guyana highlight, the headline price per tonne is not a common measure which can be used to compare value-for-money in different national deals, as it is dependent on the reference level, starting years, and timescales agreed for payment. ${ }^{17}$

However, the pathways model proposed by the CGD for Energy+, and the proposal for a CDM Fund, while still only ideas on paper, do have what in Section 2.1 we referred to as an 'endogenous' resource allocation mechanism, which uses the transaction price and quantity to determine the allocation of resources, rather than simply to disburse pre-allocated amounts. In the case of the CGD pathways model, this is through a methodology for setting national reference levels and a standard price offer, so that the ultimate resource allocation is based on the actual results achieved. In the CDM Fund model, resource allocation is based on project-based reference levels which are set according to $\mathrm{CDM}$ rules and competitive price finding, so that resource allocation builds up endogenously from the series of deals struck.

\footnotetext{
${ }^{16}$ For example in the case of the Amazon Fund, Norway allocates annual funding from its overall $\$ 1$ billion pledge, in a way that is not dependent on the pay-for-performance mechanism. Given this exogenous resource allocation, and the fact that Brazil has not 'sold' all of its emission reductions, the headline price per tonne could be set at $\$ 10, \$ 5$, or $\$ 1$ without changing the overall delivery of funding from Norway or the level of performance by Brazil.

${ }^{17}$ Comparing Norway's deals with Brazil and Guyana: both have a \$5/tonne headline, but one uses a historic benchmark and the other a pragmatically agreed rising benchmark; one relates to money destined to support a country in reducing deforestation, the other to money used to support a country in not starting - the dollar numbers are the same, but the deals are different.
} 


\section{Evaluation of the enhanced QPP Approach}

Having had a general look at QP instruments (Part 2) and having examined some early QP experiments (Part 3), we now consider how QPPs fare in the context of the three strategic objectives of the GCF mentioned in Section 1.1.1.

To do this, we shall first turn to the issue of how QPP instruments might perform with regard to the objective of promoting the paradigm shift towards low-emission and climate-resilient development pathways, as listed in the GCF Governing Instrument. We shall then evaluate the use of enhanced QPPs with regard to economic efficiency, considering the different options for enhanced QPPs and discussing their relative merits, with respect to generating 'value for money'. Finally we shall turn to some distributive justice concerns that might arise in the context of QPPs.

\subsection{Promoting the Paradigm Shift}

Can enhanced QPPs be used to promote the sort of paradigm shift envisaged in the GCF Governing Instrument? The answer is 'yes', but the precise manner of doing so depends very much on what the shift amounts to and how it is meant to be brought about.

\subsubsection{What paradigm shift (II)?}

Section 1.1.2 concluded that, in order to achieve its sustainable low-carbon development path objective, the GCF would have to promote acceptable and effective transitions in economic incentives and patterns of production and consumption. It was also suggested that the use of enhanced direct access would facilitate the acceptability of such transitions. Whether or not any particular transition is effective depends on what one is trying to achieve - a question which is beyond the scope of this Paper. It is clear, however, that certain types of transitions may be required for the paradigm shift that cannot (easily) be brought about with QP-methods. ${ }^{18}$ This is why the GCF would need to have an alternative non-QP mitigation funding stream if it is to genuinely promote the paradigm shift.

\subsubsection{Single result quantities or sets of result quantities}

However, there may be other problems facing a QPP approach. To explain this, consider the recent submission by the UK GCF member with regard to the GCF Business model Framework (UK, 2013) which stated:

While countries will define their own pathways to low-emission, climate resilient development, the Fund needs to define outcomes and measures of success which are common to all. This implies adopting a set of conventional measures of key factors, including:

- Impact on emissions, e.g. tonnes of greenhouse gases abated

- Impact on livelihoods, e.g. number of people with access to clean energy

- Energy demand reduced

- Impact on technology, e.g. number of low carbon technologies supported (units installed).

It may well be that, in order to incentivize the indicated 'paradigm shift', the QPPs would have to move beyond a single results measure - such as tonnes of (certified) emission reductions. However, it would be beyond the scope of this Paper to consider this issue further - not least in the absence of a common understanding of what would constitute such a paradigm shift - other than to highlight that having a basket of results (or a 'multidimensional result') would introduce considerable difficulties

\footnotetext{
${ }^{18}$ Such activities as: investing in policing and monitoring of illegal logging; land registration; industrial policy to build green industries; research and development; integrated food, water, and energy approaches; and targeted health and education, are not readily translatable into tonnes of emission reductions.
} 
to the process of comparing offers by NFEs, with respect to their cost effectiveness (see Section 4.2), as envisaged in the UK submission. ${ }^{19}$

\subsubsection{Macro constraints}

Transitions defined in terms of macro-level results - in other words, results that require political buyin - may impose their own constraints on the sort of (enhanced) QPPs which would be feasible or acceptable.

Because they can only be achieved through a political process, it is unlikely that 'spot-transaction'type QPPs would be adequate, for it is unlikely that a national strategy would be implemented by a country in the absence of some certainty about the required resources. To support strategic paradigm shifts, QPPs would most likely have to involve some form of forward transactions, such as arrangements which assure the recipient NFE that any results achieved will be compensated at a predictable price.

\subsection{Economic Efficiency ('value for money')}

Economic efficiency and cost effectiveness are important criteria in ensuring that the GCF achieves the highest possible reduction in emissions for a given QPP budget. In this Section we assess how different QPP options compare in terms of economic efficiency. We first discuss what efficiency means in a GCF context and then review two aspects of efficiency: the transaction efficiency of the GCF (the results it achieves in relation to the payments it makes) and its administrative efficiency (the likely transaction costs incurred in a typical QPP deal).

\subsubsection{Efficiency in a GCF context}

It is likely that the GCF will consider 'efficiency' primarily in terms of its own operations - as a performance yardstick that measures and maximizes the level of results (such as emission reductions) in proportion to GCF payments.

This narrow definition is distinct from the broader interpretation of economic efficiency common in public sector economics, which is concerned with costs and benefits for society as a whole. From society's point of view, what matters is not just the size of QPP payments in relation to results, but the full economic costs and benefits of a transaction, including those borne by the counterparty or any third parties, factoring in the external costs (or side benefits) to the environment, and ignoring the distortionary effects of taxes and subsidies.

The distinction is important, and the analytical results may not be the same. In other words, ensuring efficiency from the point of view of the GCF may not result in the most efficient outcome for society. For example, the GCF may prefer an expensive programme to which it has to contribute little, over a cheaper one that it has to finance in full.

The GCF should be aware of this, and it may wish to conduct full economic cost-benefit analyses as part of its QPP due diligence, particularly if the choice of reference level assigns a considerable fraction of programme costs to the counterparty. However, in what follows we concern ourselves primarily with the efficiency of GCF operations in the more narrow sense.

\footnotetext{
${ }^{19}$ The GCF will need to benchmark how cost effectively it is able to fulfil these criteria to ensure optimal value for money
} 


\subsubsection{Transaction efficiency}

The best way of achieving efficiency in the choice of transactions is through competitive selection. This is certainly the case from a GCF perspective. The societal outcome may depend on additional factors, such as reference levels and the allocation of costs. The design choices discussed in Part 2 suggest at least two broad models of how competition may be introduced into the selection of counterparties and/or the determination of the transaction price.

The first model involves auctions. There are many different types of auctions: forward auctions, reverse auctions, unique bid auctions, second-price auctions, and so on. The detailed modalities do not need to concern us. The important point is that potential counterparties would have to compete with one another, most likely in terms of the price they are willing to accept for delivering a certain result.

To be able to make informed comparisons, there would have to be a certain amount of uniformity across bids in terms of the reference level; that is, the contributions made by individual counterparties would have to be comparable across deals.

Other factors that may have to be standardized to facilitate comparison include: the unit of measurement, risk allocation, and certain technical standards. For example, potential transactions would have to comply with the GCF's eligibility criteria, environmental, health, and safety standards, and MRV rules. In the jargon of procurement there would have to be technical prequalification.

In the second model, competitive price discovery is introduced through a market benchmark. In this model the GCF would determine what it is willing to pay for results, according to the price of carbon in one or several emissions trading schemes. This is analogous to the oil market where prices are often expressed in relation to the price of Brent crude, or to the mortgage market where interest rates fluctuate with the Central Bank lending rate. Rather than focusing on one price, the GCF may define an index based on the listed prices in the European, Australian, and Californian trading schemes, and the secondary market for Certified Emission Reductions from the CDM. Most of these markets are liquid, competitive, and transparent. Price data for different delivery dates is readily available.

Potential counterparties would then compete on quantity and indicate the level of results they are willing to deliver at that price. This could take the form of a 'beauty contest' or the evaluation of a proposal on 'technical merit'. This is a fairly common procurement technique, which ensures transactions meet certain quality standards. As a potential alternative, the GCF could, in the case of over-subscription, ratchet up the reference level until supply meets demand. This would, de facto, be akin to an auction where bidders compete on reference levels.

It is instructive to compare the competitive model to the design structure of the Norwegian International Forest Climate Initiative (IFCI, see Section 3.1.1) and other existing QPPs. There is no significant competition in any of them. Indeed it is difficult to see how competition would be introduced into a transaction specifically designed for a single country - such as Brazil in the context of the Amazon Fund. Competition would have to occur either between different forest nations internationally, or within the Amazon basin between different sub-national counterparties. The latter would require setting state reference levels, a politically very difficult proposition.

The IFCI experience also demonstrates the difficult interplay between reference level, transaction quantity, and price. The price was set at a level (US\$5 per tonne) that was comparable to the international carbon price at the time, although it was not formally linked to a market benchmark. At that price only a limited amount of carbon could be transacted. There were few additional funders to join Norway, and Brazil therefore curtailed deforestation largely on its own. Brazil thus acquiesced to increasing the implicit reference level, in other words, to increasing the contribution it was willing to 
make on its own. That combination - of a high headline price and a high counterparty contribution was deemed to be more acceptable politically than the effective carbon price Brazil received for the overall transaction, which was around US $\$ 0.5$ per tonne.

The conclusion is that the reference level is a key aspect of a QPP instrument. The GCF may have to set reference levels using a uniform approach across transactions, and it should strive for relatively ambitious levels. A strong reference level will facilitate competition on price, increase the GCF's effectiveness in terms of leveraged results, and make transactions more acceptable relative to the market benchmark.

\subsubsection{Administrative efficiency}

The resources devoted to processing a QPP include the cost of negotiating the terms of international support agreements, project selection and management during implementation, and monitoring and verification of results.

To date there is little data on the administration costs of early experiments in QPP funds. At its launch, one of the remarkable things about the Amazon Fund was the 3 per cent administration charge that the Brazilian Development Bank (BNDES) levied. This compares very favourably with the administration costs for international funds. However, BNDES has clarified recently that this only covers specific expenses, such as travel, servicing the advisory board, auditing, and advertising, and that the staffing and other day-to-day costs of managing the Fund are paid by the Bank's own resources, and are not accounted for separately (Amazon Fund, 2011).

Nevertheless we can make some broad predictions about administration costs based on the design of different QPP approaches.

In the case of macro approaches, the cost of negotiating international support and monitoring results may be reduced with the use of a fixed price, and with monitoring at a national level using simple metrics which draw on existing systems. The national funding entity allocates resources from a single pot of money into projects, policies, and measures that it selects as good bets to reduce the emission intensity of overall economic activity. This means that the administrative burden on international funders is kept low, as they play no role in project selection.

In the case of the micro approach each project receiving funding would need to be able to demonstrate emission reduction against individually assessed baselines, and unless a fixed price approach is taken, the price would also need to be determined on a project-by-project basis. This introduces a new set of transaction costs for certifying emission reductions and setting prices at a project-by-project level. It is therefore likely that macro approaches will tend to have lower administrative costs.

The macro approach does not eliminate the cost of evaluating and implementing projects and activities, but offers the opportunity to integrate them with national systems and to localize decision making, so that more staff are paid at local rates rather than being employed within the GCF at international headquarters rates. However this does not mean the NFE can be run on a shoestring. It will need to have the capacity to play an active role in nurturing opportunities, assessing technologies, driving learning, blending different sources of funding, and linking into national debates and decision making.

In the case of micro approaches, broader scope certification of emission reductions - such as through 'programmes of action' or sectoral crediting - could reduce administration costs. Another approach could be to standardize individual deals - as in a GET FiT style support scheme for renewables procurement (see Section 3.2) - to allow them to be replicated more straightforwardly; they would, in 
effect, become a new type of international financial product which could be offered at the global level, and which countries could access to support particular classes of project.

\subsection{Equity}

While efficiency ('cost effectiveness', 'value for money') is one objective that QPP instruments can promote, it would be wrong to take it as sole evaluation criterion. Given the nature of climate change finance for developing countries - seen by many as a matter of entitlement (on the grounds of 'Common but Differentiated Responsibilities' CBDR), and not of charity - it is of particular importance to look also at issues of (in-)equity/(in-)justice in general, and distributive (in-)justice, in particular. The question to be considered at this point is thus: Do QPP instruments allow for some counterparties to get more/less than their 'fair share'?

To be clear, without some form of entitlement, it does not actually make sense to talk about a 'fair share' other than by reference to 'everything one can get in a fair manner' (in other words, to what we earlier referred to as 'endogenous resource allocation'). For example, as it stands to reason that private sector companies do not have an entitlement to be paid by the GCF or any other public sector fund, they cannot complain about not getting their 'fair share'. As long as counterparty selection and the setting of transaction price/quantity is fair private sector companies can in all fairness receive as much funding as they can obtain.

Each of the ways in which these core procedures - counterparty selection, price, and quantity setting (see Section 2.2) - can be operationalized will have its own standards of fairness (of 'fair practice'), and depending on the circumstances, it may even be possible to choose between them in terms of which is fairest (for example, in terms of degrees of competitiveness). However, there are no private (sector) entitlements, apart from the entitlement to fair (competitive) process.

In the case of countries - and of National Funding Entities used as country conduits for GCF funding - the situation is not quite the same, for they are acknowledged to have Common But Differentiated Responsibilities and Respective Capabilities (CBDR/RC), which can be used to derive 'fair CBDR/RC shares'. The general question then is: what happens if these entitlements entail fair allocations that differ from the (endogenous) allocations resulting from fair enhanced QPPs?

In particular, it is clear that that fair CBDR/RC shares would most likely differ from the shares given by an endogenous allocation, say by a competitive QPP instrument, even if that were applied in a perfectly fair manner. So, in broad terms, the key equity question arising in the context of fair enhanced QPP instruments is: Is there is an inevitable conflict between their endogenous resource allocations, and fair entitlement (such as CBDR/RC) shares? Section 5.1.1 will make a proposal aimed at avoiding such direct conflicts. 


\section{Conclusions}

\subsection{The role of Enhanced QPPs in the GCF}

Quantity Performance Payments for results (QPPs) can play a role in Enhanced Direct Access (EDA) first and foremost because they can be carried out in the absence of any information relating to operational funding decisions (such as project and programme approvals). But can QPPs do this while also abiding by the three strategic objectives identified in Section 1.1.1: equity, efficiency and effectiveness, and promoting a paradigm shift towards low-emission and climate-resilient development pathways? If so, what is the best QPP model?

The answers based on the analysis presented above are: 'yes', and 'it depends on the socio-economic transition that is targeted'.

\subsubsection{Equity}

The most general answer can be given with respect to the issue of equity - or to be more precise, how enhanced QPPs should be structured so as to lead to an equitable distributive outcome - for it can be framed without reference to particular socio-economic transitions.

Concerning the potential inconsistency between entitlement-based allocations and endogenous allocations through fair QPPs (Section 4.3), one way of dealing with issues of distributional justice between recipient countries in the context of enhanced QPPs is to separate two distinct streams for mitigation funding: a QP-stream, and an alternative ('entitlement') stream, with the former to be used for fair (enhanced) QPPs, and the latter for other funding methodologies (most likely in conjunction with an exogenous resource allocation framework, based on some form of entitlements).

In other words, the idea is to separate entitlement-based funding from funding with fair endogenous resource allocations (such as those arrived at through competitive transactions). Note, incidentally, that this also allows for a separation of the issue of entitlement-based distributive justice and efficiency qua outcome of competitive transactions.

\subsubsection{Efficiency}

The main design decision in terms of efficiency is the trade-off between transaction efficiency (which would favour competitive selection processes such as auctions) and administrative efficiency (which may favour softer forms of competition, such as standardized deals). There is much to be said for competitive project selection and/or price setting. At the same time, however, there are reasons why auctions are usually confined to the commercial world and play little or no role in development assistance. The need for broad political ownership, the difficulty of preparing bids through a democratic process, and the uncertainty involved make formal auctions difficult. This suggests that the GCF may, at least initially, opt for a model that does not include price competition. One model would be to combine market benchmarking as a way of price determination with a (rigorous) beauty contest for counterparty selection. However, auctions could be considered from the outset for any QPPs involving private sector counterparties.

\subsubsection{Paradigm shift}

There are two main conclusions to be drawn with respect to the question of whether enhanced QPPs can be used in achieving the paradigm shift called for in the objectives of the GCF.

First, QPPs can be used for this purpose, but they are not sufficient, and would have to be complemented by a non-QP mitigation funding stream. 
Second, those transitions that can be brought about through quantitative performance incentives will require tailor-made QPP instruments ('horses for courses'): there is no single 'optimal' QPP instrument. Different types of transitions will require different instruments.

\subsection{Two Examples}

The earlier discussion (Part 3) provides some models of what fair enhanced QPP instruments might be, both in the context of macro- or micro- results, and in the context of competitive or noncompetitive transaction methodologies.

\subsubsection{An enhanced macro model}

Norway's International Forest Climate Initiative, together with the proposals developed by the Center for Global Development (Section 3.1), can be used to illustrate an enhanced QPP approach which is based on results measured at a macro level and with a fixed price transaction methodology.

The idea would be for the GCF to use general methods for determining sets of sectoral pathways which, when applied to (eligible) countries, determine the minimum ('expected') performance level from which performance-related payments are made. The price, in turn, would be fixed by dividing the potential total of performance sought across eligible countries by the available funding. The actual transactions would be payments made each year to countries, based on their performance above the minimum pathway. Countries would thus stand to 'make a profit' on achieving low-cost emission reductions (such as through energy efficiency), while at the same time they might need to find additional domestic funding, or low-cost loans, to bring down the cost of more expensive actions.

While it is clear that this type of instrument may not deliver an efficient solution (generating the most verified $^{20}$ reductions for the available funds, see Section 4.2) for the $\mathrm{GCF}^{21}$ there may be good reasons for choosing this sort of model, particularly if the funding has certain strategic aims (Section 4.1) such

\section{Box 1. The Enhanced Macro Model in formal terms}

: country $k$ 's measured and verified sectoral level for period $t$;

$: k$ 's expected level for $t$;

$: k$ 's ambitious level for $t$;

$: k$ 's verified eligible performance in $t$ :

Country $k$ 's maximum eligible performance in $t$ :

Total eligible performance level in $t$ :

: funding available for $t$;

Unit disbursement ('price') for period $t$ :

Quantity Performance Payment to $k$ for the performance in $t$ :

\footnotetext{
${ }^{20}$ Note: 'verified' here does not imply that the reductions are tradable (e.g. as in 'CERs' or 'VERs'), but simply that they were submitted to an MRV procedure.

${ }^{21}$ A phased approach to price setting - starting with a lower price and gradually increasing it - might enhance the efficiency of the instrument.
} 
as: assisting countries to go faster; avoiding, say, lock-in of high-carbon infrastructure; and in turn enabling more rapid development of the technologies themselves.

The key question in any such scheme would be whether it is (seen to be) fair. This, in turn, essentially boils down to the question of whether the reference methodologies are perceived to be fair, as they are the key determinants of (i) the difficulty of reaching and exceeding the minimum performance pathway, and (ii) the resulting resource allocation. While this cannot be the place to discuss what such fair methodologies would have to look like in detail, it seems reasonable to think that universal applicability, both of the methodologies and the price, would enhance (perceived) fairness.

\subsubsection{An enhanced micro model}

The CDM Fund proposals discussed in Section 3.2 lend themselves to illustrating an enhanced QPP approach based on micro-level results, with a fully competitive transaction methodology.

As things stand, these proposals are focused on what we referred to as QP Finance (Section 1.2) - that is, on engaging directly with private sector project developers, and as such would probably fit in best with the GCF Private Sector Facility. ${ }^{22}$

While the UNFCCC study (Vivid Economics, 2013b) does envisage the possibility of focusing on certain project types and geographies which differ from the historic patterns of supply within the $\mathrm{CDM},{ }^{23}$ it does not specify how transactions (price/volume/counterparty) would be determined. For the sake of argument, let us simply assume that the transaction price and volume are determined by a reverse auction of forward contracts. In other words, project developers would be able to put bids on how many tonnes they would wish to deliver to the GCF at what price and at what time; the GCF could issue contracts in accordance with the best value for money.

Would it be possible to transform this into an enhanced QPP model, admitting bidding from National Funding Entities? In principle yes, but the real question is whether it would be useful, and there are at least two contexts in which it could be.

For one, it could allow private-sector project developers (from developing countries), to access GCF funding through a national intermediary, as envisaged in the recent Delhi Vision Statement by the Indian Government. Thus project developers could come to (conditional) arrangements with National Funding Entities which would then join the GCF bidding rounds based on these arrangements. ${ }^{24}$

Second, provided that certain macro-level results are comparable with the sort of results associated with the traditional CDM methodologies - maybe some form of sectoral results - NFEs might be well-placed to bid-in these results to the GCF auctions. Of course, that would only happen if the potential obstacles discussed in Part 4 were adequately addressed.

The advantage of this sort of model would be that it can lead to a more efficient way of using GCF resources, and would be seen as fair, provided the competition is carried out in a fair manner. What it may not be able to address adequately are some of the GCF's additional strategic objectives.

The two sample models demonstrate the potential for enhanced QPP instruments - whether involving competitive or other types of transactions or, for that matter, micro- or macro-level results - to support the GCF in reaching its strategic objectives.

\footnotetext{
${ }^{22}$ For more on the use of QP financing, see Ghosh et al. (2012).

${ }^{23}$ The UNFCCC study considers two QP price-setting mechanisms: purchasing at prevailing market price, setting a 'price floor'.

${ }^{24}$ A presentation by the Federation of Indian Chambers of Commerce and Industry during a consultation on the Delhi Vision Statement made it perfectly clear that FICCI would prefer to have access to a National Funding Entity rather than having to access GCF funding directly.
} 


\section{References}

Adaptation Fund (2009). 'Operational Policies and Guidelines for Parties to Access Resources from the Adaptation Fund', Adaptation Fund Board.

Amazon Fund (2011). Annual Report: Basic Concepts

Amazon Fund (2012a). Portfolio Report, Overview of the Projects Submitted to the Amazon Fund, Amazon Fund's Management Department, AMA/DEFAM, 30 September 2012. www.amazonfund.gov.br.

Amazon Fund (2012b). Portfolio Report, Amazon Fund's Management Department, AMA/DEFAM, 30 September 2012. www.amazonfund.gov.br.

Barr, R., S. Fankhauser and K. Hamilton (2010). 'Adaptation Investments: A Resource Allocation Framework', in: Mitigation and Adaptation Strategies for Global Change, 15(8): 843-58.

Birdsall, N. and Savedoff, W. D. (2011). Cash On Delivery: A New Approach to Foreign Aid, Center for Global Development, Washington DC.

Birdsall, N. and Savedoff, W. D. (2013). 'A Critical Moment for COD Aid or "How to Be Patient When It Matters" ', Global Development: Views from the Center, Centre for Global Development, Washington DC.

Bowen, A. and Ranger, A. (2009). 'Mitigating climate change through reductions in greenhouse gas emissions: the science and economics of future paths for global annual emissions', Policy Brief, Grantham Research Institute on Climate Change and the Environment, London, UK, December

Carbon Tracker (2013). 'Unburnable Carbon 2013: Wasted Capital and Stranded Assets', Carbon Tracker Initiative and Grantham Research Institute on Climate Change and the Environment, London, UK.

CDM (2012). 'Climate Change, Carbon Markets and The CDM: A Call To Action', Report of the High-Level Panel on the CDM, Policy Dialogue.

Ciplet, D., B. Müller, and J Timmons Roberts (2010). 'How many people does it take ... to administer longterm climate finance?' ecbi Policy Report.

De Nevers, M. (2012). 'FORMA and fCPR: Accelerating a Performance-Based Payment System for REDD+', CGD Policy Paper 006, Washington, D.C.: Center for Global Development.

Deutsche Bank (2011). 'GET FiT Plus: De-Risking Clean Energy Business Models in a Developing Country Context', DB Climate Change Advisors.

Dietz, S. and Fankhauser, S. (2010). 'Environmental Prices, Uncertainty and Learning', in: Oxford Review of Economic Policy, 26: 270-84.

Doda, L.B. (2012). 'Evidence on $\mathrm{CO}_{2}$ emissions and business cycles', Working paper, Grantham Research Institute on Climate Change and the Environment, London, UK.

Edwards, R. (2011). 'The Green Climate Fund and the implementation of Emission Reduction Underwriting Mechanisms', Climate Change Capital Think Tank.

Energy Plus Partnership (2012). Energy+ Country Partnership Strategy, International Energy and Climate Initiative

GEF (2011) System for Transparent Allocation of Resources (STAR), Global Environment Fund.

Gomez-Echeverri, L. (2010) 'National Funding Entities: Their role in the transition to a new paradigm of global cooperation on climate change', ecbi Policy Report, October.

Ghosh A., B. Müller, W. Pizer, and G. Wagner (2012). 'Mobilizing the Private Sector: Quantity-Performance Instruments for Public Climate Funds' Oxford Energy and Environment Brief, OIES, August.

Government of Norway (2012) 'Norway's Submission to the UNFCCC on Views on Results-Based Finance for REDD+', March.

Klingebiel, S. (2012). 'Results Based Aid - a New Aid Label or a Potential for More Impact', NORRAG News, No. 47, 76-8.

Kreibehl, S. (2012). GET FiT - an innovative PPP, August 2012 - Presentation; Deutsche Bank Climate Advisors 
Mucci, M. (2012). Measurement, Reporting and Verification (a note on the concept with an annotated bibliography), IISD.

Müller, B. and P. Ghosh (2008). 'Implementing the Bali Action Plan: What role for the CDM?', Oxford Institute for Energy Studies Energy and Environment Comment, October.

Müller, B. (2009). 'Additionality in the Clean Development Mechanism: Why and What?', Climate Strategies and Oxford Institute for Energy Studies EV 44, Oxford.

Müller, B. (2011). 'Enhanced Direct Access: Submission to the Transitional Committee on the issue of Thematic Funding Windows (Workstreams II \& III)', Submitted through the UNFCCC constituency of Research and Independent NGOs, OIES: Oxford, August.

Norway Environment Ministry (2012). 'Norwegian Climate Policy', Report No. 21 (2011-2012) to the Storting (White Paper) Summary, Ministry of the Environment, Government of Norway.

Norway Foreign Affairs Ministry (2011). An International Initiative to accelerate Efforts to Promote Universal Access to Energy, Energy Efficiency and Low-Carbon Development, Ministry of Foreign Affairs, Government of Norway, 24 June.

Parks, B. and Z. Rice (2013). Does the 'MCC Effect' Exist?, Results from the 2012 MCA Stakeholder Survey, Center for Global Development, Washington DC.

Streck, C. (2011). 'The Concept of Additionality under the UNFCCC and the Kyoto Protocol: Implications for Environmental Integrity and Equity',

Tipper, R. et al (2011). 'Real-Time Evaluation of Norway’s International Climate and Forest Initiative', Oslo: Norad (Evaluation report no. 12/2010).

UK (2013) 'The Green Climate Fund: Operational objectives - a UK perspective', Comments on behalf of $\mathrm{Mr}$ Nick Dyer (UK) on BMF, 28 Feb.2013; in Views by Members and Alternate members of the Board of the Green Climate Fund On Questions related to the Fund's Business model framework, Interim Secretariat of the GCF.

Vivid Economics (2013a). 'Results-based Finance. An Analytical Guide', Report prepared for ESMAP, World Bank, Washington DC.

Vivid Economics (2013b). 'The Market Impact of a CDM Capacity Fund', Final Report, UNFCCC, June 2013.

Wheeler, D. (2012). 'Energy+ Country Performance Ratings 2001-2010', CGD Working Paper 301, Center for Global Development, Washington DC, July.

Wheeler, D., D. Hammer, and R. Kraft (2012). ' fCPR: Forest Conservation Performance Rating for the PanTropics', Center for Global Development Working Paper No. 294.

World Bank (2010). World Development Report 2010: Development and Climate Change. World Bank, Washington DC.

World Bank (2012). 'Guyana REDD-Plus Investment Fund Trust Fund Financial Report', World Bank Group Financial Intermediary Funds, GRIF Trust Fund.

Yogita, M, L. Johannes, and G. Kumar (2010). Output-Based Aid: Lessons Learned and Best Practices, Washington D.C.: World Bank.

Zadek, S., M. Forstater, F. Polacow, and J. Boffino (2009). Radical Simplicity in Designing National Climate Institutions: Lessons from the Amazon Fund, Account Ability, London.

Zadek, S., M. Forstater, E. Ritchkin, S. Fakir, J. Kornik, and J. Haas (2010). 'Unlocking South Africa's Green Growth Potential: the South African Renewables Initiative', Department of Trade and Industry, Government of the Republic of South Africa, Pretoria, December.

Zadek, S., M. Forstater, and F. Polocow (2010). 'The Amazon Fund: Radical Simplicity and Bold AmbitionInsights for Building National Institutions for Low Carbon Development', Avina Foundation, November.

Zadek, S., M. Forstater and F. Polocow (2011). 'Win-Win-Win?: Testing an Approach to Catalysing Climate, Community and Economic Sustainability at the Core of the Amazon, Amazonas Sustainable Foundation (FAS).

Zarin, D., A. Angelsen, S. Brown, C. Loisel, and L. Peskett (2009). 'Reducing Emissions from Deforestation and Forest Degradation (REDD): An Options Assessment Report', Meridian Institute for the Government of Norway. 